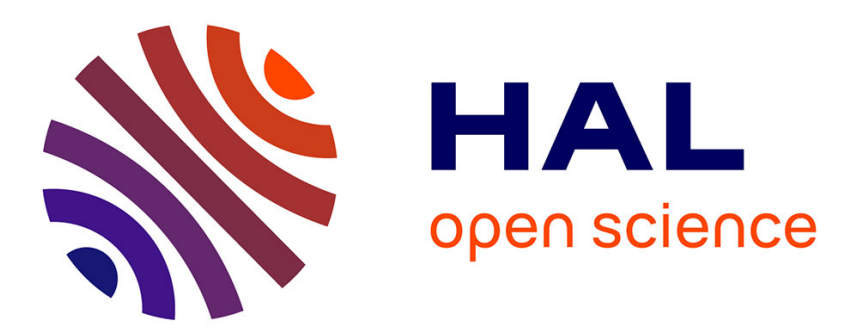

\title{
Analyses of extreme swell events on La Réunion Island from microseismic noise
}

Céline Davy, Guilhem Barruol, Fabrice R. R. Fontaine, Emmanuel Cordier

\section{To cite this version:}

Céline Davy, Guilhem Barruol, Fabrice R. R. Fontaine, Emmanuel Cordier. Analyses of extreme swell events on La Réunion Island from microseismic noise. Geophysical Journal International, 2016, 207 (3), pp.1767-1782. 10.1093/gji/ggw365 . hal-01389904

\section{HAL Id: hal-01389904 https://hal.univ-reunion.fr/hal-01389904}

Submitted on 9 Nov 2016

HAL is a multi-disciplinary open access archive for the deposit and dissemination of scientific research documents, whether they are published or not. The documents may come from teaching and research institutions in France or abroad, or from public or private research centers.
L'archive ouverte pluridisciplinaire HAL, est destinée au dépôt et à la diffusion de documents scientifiques de niveau recherche, publiés ou non, émanant des établissements d'enseignement et de recherche français ou étrangers, des laboratoires publics ou privés. 


\title{
Analyses of extreme swell events on La Réunion Island from microseismic noise
}

\author{
C. Davy, ${ }^{1}$ G. Barruol, ${ }^{1}$ F.R. Fontaine ${ }^{1}$ and E. Cordier ${ }^{2}$ \\ ${ }^{1}$ Laboratoire GéoSciences Réunion, Université de La Réunion, Institut de Physique du Globe de Paris, Sorbonne Paris Cité, UMR CNRS 7154, \\ Université Paris Diderot, 15 avenue René Cassin, CS 92003, F-97744 Saint Denis cedex 9, France. E-mail: celine.davy@univ-reunion.fr \\ ${ }^{2}$ Observatoire des Sciences de l'Univers à La Réunion (OSU-R/UMS 3365, Université de la Réunion, CNRS), La Réunion, France
}

Accepted 2016 September 25. Received 2016 September 15; in original form 2016 May 19

\begin{abstract}
S UMMAR Y
Ocean wave activity excites seismic waves that propagate through the solid earth, known as microseisms, which, once recorded on oceanic islands, can be used to analyse the swell. Here, we analyse the microseismic noise recorded in different period ranges by the permanent seismic station RER on La Réunion Island and by a temporary network of 10 broad-band seismic stations deployed on the island to analyse extreme swell events. We perform a comparative analysis of cyclonic and austral swell events by analysing not only the primary (PM, $\sim 10$ 20 s period) and secondary ( $\mathrm{SM}, \sim 3-10 \mathrm{~s}$ ) microseisms but also the long-period secondary microseisms (LPSMs, $\sim 7-10 \mathrm{~s}$ ), which may result from the interaction between incident ocean waves and the reflected waves off the coast. We compare the microseismic observations with buoy data when available and with hindcasts from numerical ocean wave models. We show that each cyclone is characterized by its own individual signature in the SM, which depends not only on its distance and intensity but also on its dynamics and trajectory. Thus, the SM contains relevant information for cyclone detection and monitoring. Analysing the PM and the LPSM, and comparing it to direct buoy observations and/or wave numerical models allows characterizing the local impact of the swell with the island in terms of amplitude, period, and sometimes, direction of propagation, making possible to use a seismic station as an ocean wave gauge. The microseisms, which link the atmosphere, the ocean and the solid Earth, can thus provide valuable observations on extreme swell events, in addition to oceanic and meteorological data.
\end{abstract}

Key words: Time-series analysis; Instrumental noise; Broad-band seismometers; Seismic monitoring; Statistical seismology; Indian Ocean.

\section{INTRODUCTION}

Depending on the season, La Réunion Island can be hit by two kinds of swell. In summer (from November to March), the southwest Indian Ocean basin may be affected by tropical storms that may develop as tropical cyclones. In the Southern Hemisphere, cyclones develop over the warm waters in the tropical regions, with winds blowing clockwise around the depression because of the Coriolis effect. They generally move southward towards higher latitudes where colder surface waters reduce their energy. Even if cyclones may develop at large distance from La Réunion Island, the cyclonic swell can reach and hit the coasts of the island, producing large damages. The island is mostly impacted on its northern coast by the cyclonic swell generated by tropical storms that develop and move in the area.

In winter (from May to September), the southern coasts are mostly impacted by the austral swell that is generated by deep depressions moving from west to east around the Antarctic continent, between $40^{\circ}$ and $60^{\circ}$ of latitude south. The swell generated in these areas is characterized by long fetches and spreads northwards to northeastwards into the Indian Ocean. It takes about three to four days to reach La Réunion, at a distance of 3000-4000 km away. The austral swell is characterized by long periods (between 10 and $20 \mathrm{~s}$ ) and mean heights of 3-4 m as it hits the south and west coasts of $\mathrm{La}$ Réunion. Such swell events occur 15-25 d each year and can reach up to ten metre in height as they break on the shore.

Both types of swell can have strong societal and environmental consequences and large impact on the coastal infrastructures but they also represent a large source of renewable energy. Yet, La Réunion Island is still poorly instrumented in terms of swell monitoring, with only scarce ocean wave gauges, and only few available data recorded during extreme swell events due to instrumental failures. In order to quantify the swell parameters of large events that affected the coasts of La Réunion Island and to get swell data in poorly instrumented areas, we used seismic data as a swell proxy. We take the opportunity of the presence of permanent seismic stations 
and of temporary deployments of terrestrial seismic instruments on the island to characterize several extreme swell events from the microseismic noise that we combine with direct wave observations and numerical modelling.

Microseisms are generated by ocean waves activity and can be recorded worldwide by broadband seismic stations as ground vibrations of a few microns in amplitude (Stutzmann et al. 2009). Seismic noise is dominated by two kinds of microseisms, that develop in different frequency ranges and that are generated by different physical processes, namely the primary and secondary microseisms (PM and SM). PMs have the same periods as the ocean swell (between 8 and $20 \mathrm{~s}$ ) and are generated through direct interaction of swellinduced pressure variation with the sloping seafloor in coastal areas (Hasselmann 1963). Secondary microseisms (SMs) are recorded worldwide with more energy and are characterized by a dominant period of half the period of the ocean waves (typically between 3 and $10 \mathrm{~s}$ ). They are induced by depth-independent second-order water pressure fluctuations on the seafloor, which are generated by the interference of swells of similar periods that travel in opposite directions (Longuet-Higgins 1950). From numerical modelling, Ardhuin et al. $(2011,2012)$ showed that SM generated on the seafloor by partially standing waves developing at the ocean surface may occur under three situations: in a single storm with a broad ocean wave directional spectra (class I), by the interaction between an incoming swell with its own coastal reflection (class II), and finally, by two distinct swells of similar periods that travel in opposite directions (class III).

Microseisms are dominated by Rayleigh waves (Lacoss et al. 1969; Tanimoto \& Alvizuri 2006) and $P$ waves (Barruol et al. 2006; Gerstoft et al. 2008; Koper et al. 2010) that can be observed far from their generation areas, but recent studies have shown that Love waves (Nishida et al. 2008; Tanimoto et al. 2015) can also be detected in the SM frequency band.

SM noise sources have been located in near-coastal shallow waters, related to coastal swell reflection with the incident swell (Bromirski \& Duennebier 2002; Bromirski et al. 2013), but also in deep waters, related to interactions between swells from two distinct storms (Obrebski et al. 2012; Beucler et al. 2014). For the Indian Ocean, it has been recently shown that the dominant SM sources are located at large latitudes in the south of the ocean basin, associated with large atmospheric low-pressure systems moving from west to east around Antarctica (Davy et al. 2015), but also that SM can be generated by major tropical storms occurring at intermediate latitudes in tropical regions (Davy et al. 2014).

Although SM may provide information related to distant storms, partially standing waves may also be generated by reflection of the incident swell on the coast (Bromirski \& Duennebier 2002). When high-amplitude ocean waves of $12-25 \mathrm{~s}$ period generated by a distant storm impact a shoreline, interactions of incident waves with opposing components reflected from the coast may generate a local source of long-period secondary microseism, referred here as LPSM but also defined as LPDF (Bromirski et al. 2005; Beucler et al. 2014; Koper \& Burlacu 2015). Analysing the seismic noise in the PM or the LPSM frequency bands, which are both generated near the coast, may therefore provide a way to characterize the ocean waves locally in terms of amplitude, period, and sometimes, direction of propagation, as well as the local impact of swell on the shore (Barruol et al. 2016).

In this study, we analysed the microseismic noise recorded during extreme swell events by the permanent GEOSCOPE seismic station RER and by a temporary network of ten seismic stations deployed on La Réunion Island between 2012 and

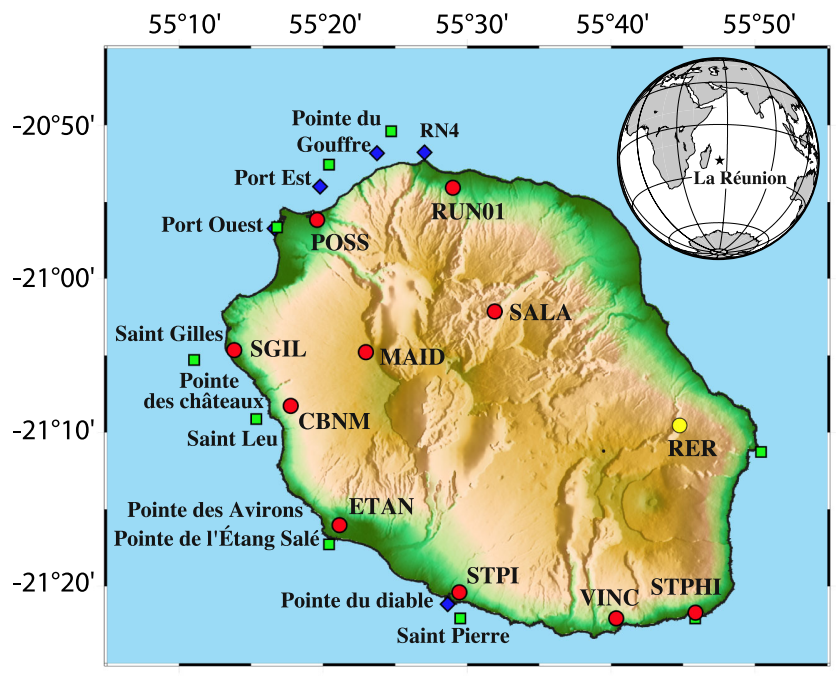

Figure 1. Map of La Réunion Island with the location of the permanent GEOSCOPE seismic station RER (yellow circle) and the 10 seismic stations temporarily deployed in the frame of the RHUM-RUM experiment (red circles) analysed in this paper. Are also plotted the available ocean waves gauges (blue diamonds) and the grid points used in the local ocean wave model SWAN (green squares).

2015 in the frame of the RHUM-RUM experiment (Barruol \& Sigloch 2013).

In the following sections, after presenting the seismic network, the data and the method used to characterize and quantify the swellinduced microseismic noise, we analysed the seismic noise generated by the tropical cyclones and the austral swell. We considered as examples the cyclones Gamède (2007), Dumile (2012), Felleng (2013) and Bejisa (2014), and three different austral swell events that were hitting La Réunion in May 2007, August 2013 and June 2014. Our study focuses on the signature of both the SM and the PM frequency bands for each event, and also on the LPSM frequency band when a clear class II SM noise source related to coastal reflection is found.

This approach allows us to discuss the spatial variations of the seismic noise level recorded on-land across La Réunion Island during extreme swell events to characterize the swell impact on the different coasts of the island, and the possible inland variation of the seismic noise. Comparing microseismic noise with buoy direct observations and with the hindcast numerical models of local ocean waves enables us to elaborate transfer functions that may link the height of the swell to the microseismic noise amplitude. This represents a way to get precious swell data in area devoid of wave gauges and to develop continuous swell observations in remote areas (e.g. Iafolla et al. 2015).

\section{DATA AND METHODS}

\subsection{Seismic stations}

To perform a comparative analysis of the extreme swell events in La Réunion Island from the microseismic noise, we used the permanent seismic station RER of the global network GEOSCOPE, installed in a tunnel in the eastern part of the island since February 1986 (Fig. 1, in yellow). This station is equipped with Streckeisen STS-1 sensors, a Quanterra Q330 digitizer and a Metrozet E300 Electronics acquisition. 
Table 1. Location and recording periods of the broad-band seismic stations in La Réunion. Due to technical failures and recording capacities, there are some recording gaps at some stations. The sensor types are summarized by STS-1 for the Streckeisen STS-1, T-240 for the Nanometrics Trillium 240, by T-Compact for the Nanometrics trillium Compact $120 \mathrm{~s}$ and by CMG-3ESPC for the Guralp CMG3-ESPC $120 \mathrm{~s}$.

\begin{tabular}{lcccccc}
\hline Station & Lat. $\left({ }^{\circ} \mathrm{N}\right)$ & Long. $\left({ }^{\circ} \mathrm{E}\right)$ & Sensor type & Shore distance $(\mathrm{km})$ & Start recording & End recording \\
\hline RER & -21.1712 & 55.7399 & STS-1 & 9.0 & $1986-02-10$ & Permanent \\
& & & & & 2.7 & $2013-01-16$ \\
GEOSCOPE station \\
CBNM & -21.1376 & 55.2953 & T-240 & 15.0 & $2012-10-25$ & $2015-06-09$ \\
MAID & -21.0797 & 55.3831 & T-240 & 0.9 & $2013-01-29$ & $2015-06-05$ \\
POSS & -20.9361 & 55.3271 & T-240 & 30.0 & $2013-03-12$ & $2015-06-04$ \\
SALA & -21.0357 & 55.5325 & T-240 & 1.7 & $2012-05-18$ & $2015-01-15$ \\
ETAN & -21.2672 & 55.3526 & T-Compact & 1.3 & $2012-05-11$ & $2015-01-13$ \\
SGIL & -21.0773 & 55.2304 & T-Compact & 0.2 & $2012-05-10$ & $2015-01-13$ \\
STPHI & -21.3620 & 55.7644 & T-Compact & 1.2 & $2012-09-20$ & $2015-01-13$ \\
STPI & -21.3398 & 55.4915 & T-Compact & 1.7 & $2011-07-05$ & $2016-01-25$ \\
RUN01 & -20.9009 & 55.4835 & CMG-3ESPC & 1.0 & $2012-08-23$ & $2015-05-31$ \\
VINC & -21.3684 & 55.6729 & T-Compact & & &
\end{tabular}

Table 2. Extreme swell events selected for this study and their meteorological characteristics. Source: www.cyclonextreme.com and Météo France Réunion.

\begin{tabular}{|c|c|c|c|c|c|c|}
\hline & Event & $\begin{array}{l}\text { Period of } \\
\text { activity }\end{array}$ & $\begin{array}{l}\text { Date of maximum } \\
\text { intensity (UTC) }\end{array}$ & $\begin{array}{c}\text { Ocean waves } \\
\text { data }\end{array}$ & $\begin{array}{l}\text { Pressure minimum } \\
\qquad(\mathrm{hPa})\end{array}$ & $\begin{array}{l}\text { Wind on } 10 \mathrm{~min} \\
\left(\mathrm{~km} \mathrm{~h}^{-1}\right)\end{array}$ \\
\hline \multirow[t]{4}{*}{ Tropical cyclone } & Gamède & 2007 Feb 20 to Mar 6 & 26 Feb-00h & WaveWatchIII & 935 & 176 \\
\hline & Dumile & 2012 Dec 30 to 2013 Jan 6 & $04 \mathrm{Jan}-00 \mathrm{~h}$ & Buoy RN4 & 967 & 138 \\
\hline & Felleng & 2013 Jan 26 to Feb 4 & $30 \mathrm{Jan}-12 \mathrm{~h}$ & Buoy RN4 & 937 & 212 \\
\hline & Bejisa & 2013 Dec 29 to 2014 Jan 8, 2014 & $31 \mathrm{Dec}-00 \mathrm{~h}$ & Buoy RN4 & 941 & 203 \\
\hline \multirow[t]{3}{*}{ Austral swell } & 2007 & 2007 May 10-17 & 12 May-23h & Ocean wave gauge (Saint Pierre) & & \\
\hline & 2013 & 2013 Aug $17-23$ & 21 Aug-09h & SWAN & & \\
\hline & 2014 & 2014 Jun $18-28$ & 22 Jun-10h & SWAN & & \\
\hline
\end{tabular}

We also used a temporary network of ten broadband seismic stations (Fig. 1, in red) that were deployed on La Réunion Island between 2012 and 2015 in the frame of the RHUM-RUM research program (Réunion Hotspot and Upper Mantle - Réunions Unterer Mantel) to investigate the mantle structure beneath the active hotspot of La Réunion (Barruol \& Sigloch 2013). Five of these stations were equipped of Nanometrics Trillium compact seismometers with Nanometrics Taurus acquisitions, four others stations were equipped with Nanometrics Trillium 240 sensors and with Reftek RT130 digitizers and one seismic station was equipped with a Guralp CMG3ESPC $120 \mathrm{~s}$ sensor with a Nanometrics Taurus acquisition (see Table 1).

All these seismic stations continuously measured the signal proportional to ground velocity along the three components (vertical, NS and EW horizontal directions), at sampling frequencies of $100 \mathrm{~Hz}$, (except at RER where the data are provided at $20 \mathrm{~Hz}$ ). GPS receivers provided precise dating of seismic recordings.

Seismic data used in this work are available at the French data archive centre GEOSCOPE (http://geoscope.ipgp.fr/) for the station RER and at the RESIF French archive centre (http://seismology.resif.fr) for the RHUM-RUM stations, under the seismic network code YV (Barruol \& Sigloch 2012, 2013).

\subsection{Data selection}

We selected few extreme swell events that impacted La Réunion during the last years (Table 2). We first chose two reference events: the cyclone Gamède (February 2007) and the exceptional austral swell event of May 2007, which have been recorded by the permanent GEOSCOPE seismic station RER. Then, we selected more recent extreme swell events, which have been recorded by the temporary RHUM-RUM network deployed on the island between 2012 and 2015: the three tropical cyclones Dumile (early
January 2013), Felleng (late January 2013) and Bejisa (early January 2014), and two austral swell events that occurred in August 2013 and June 2014. Meteorologic data on the cyclonic events such the location of the storm centre, the atmospheric pressure $(\mathrm{hPa})$, the wind velocity (knots) and the intensity of the meteor are provided every $6 \mathrm{hr}$ (in UTC) by Météo France Réunion (http://www.meteofrance.re/cyclone/). When available, we used direct observations of the swell from the non-directional ocean wave gauges of Saint Pierre located in the south of the island (for the May 2007 event) and Le Port on the west coast (for the swell events of August 2013 and June 2014), and from the buoy RN4 temporarily installed on the north shore of La Réunion (for the cyclones Dumile, Felleng and Bejisa). These buoys are located by blue diamond on Fig. 1. When no direct buoy observation was available, we used hindcast runs of the global ocean wave model WaveWatchIII at 0.5 degrees of resolution to characterize the significant wave height during the cyclone Gamede (2007). Finally, we used the data from the global ocean wave model WaveWatchIII to force a local SWAN wave model (Booij et al. 1999) at a resolution of around $500 \mathrm{~m}$, to analyse the local impact of the austral swell events of August 2013 and June 2014. Fig. 1 shows as green squares the model nodes used to compare the wave parameters to the closest seismic station.

\subsection{Analyses of microseismic noise}

The microseisms were first analysed from their spectral content by calculating the power spectral density of seismic noise converted into decibels with respect to acceleration as a function of the period of the signal (Herrmann 2013). This enables to provide a quantitative estimate of the mean wave period parameter $T p$. Spectra computed during extreme swell events show high noise level in the microseismic frequency band in comparison with the high and low noise bounds observed worldwide at permanent 

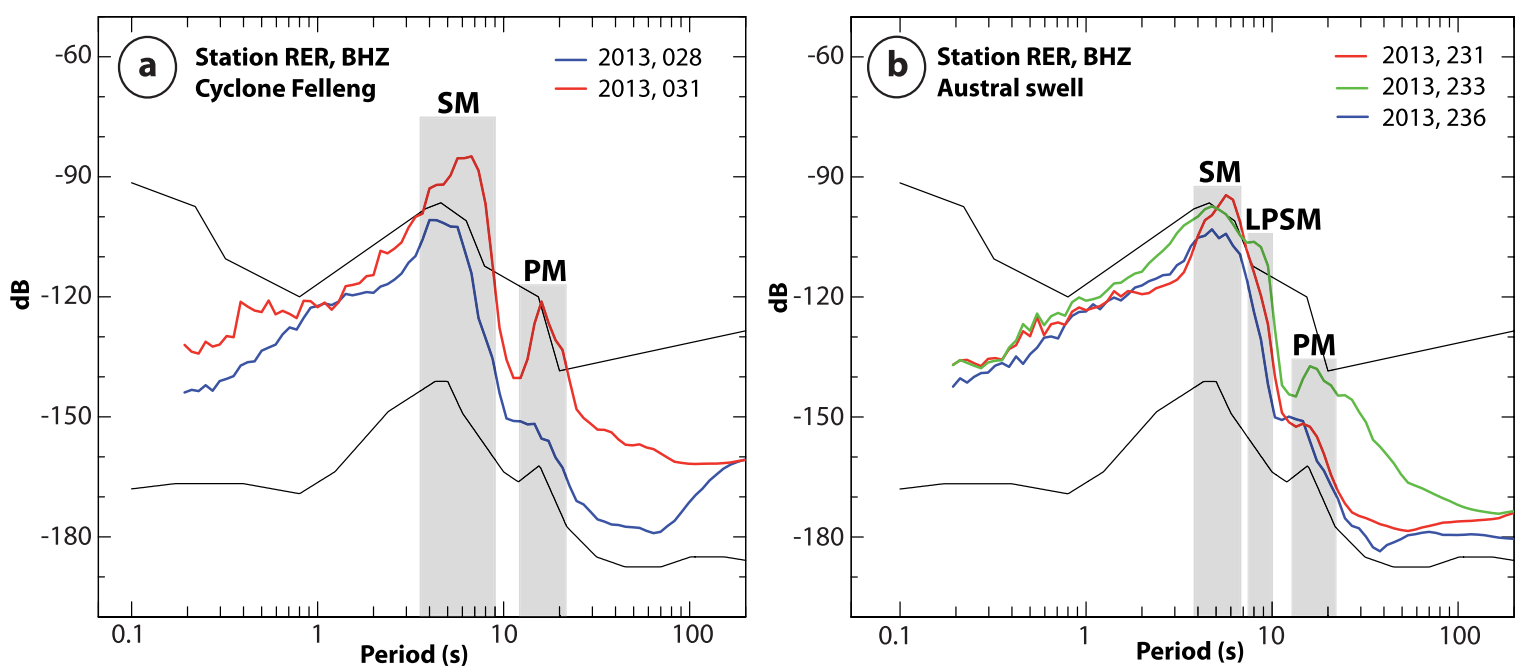

Figure 2. (a) Power spectral density of seismic noise converted into decibels with respect to acceleration as a function of wave period (in s), recorded at the vertical component (BHZ) of RER station, before (blue line) and during (red line) the cyclone Felleng in January 2013. Frequency bands corresponding to primary (PM) and secondary (SM) microseisms are shaded in grey. During the cyclone event, the noise clearly increases in both frequency domains. The black lines correspond to the high and low noise bounds observed worldwide at permanent seismological stations (Peterson 1993). (b) Power spectral density of seismic noise converted into decibels with respect to acceleration as a function of wave period (in s), recorded at the vertical component (BHZ) of RER station, before (red line), during (green line) and after (blue line) an austral swell episode occurring in August 2013. LPSM indicates the long-period secondary microseism likely induced by swell reflection. Interestingly, the SM is maximum before the swell arrival indicating the distant source of the storm in the austral ocean and the PM is maximum as the swell hits the coast.

seismological stations (Peterson 1993). This enables us to determine the different frequency bands of the PM, the SM and the LPSM, which are analysed in this study. The examples presented in Fig. 2 show noise spectra recorded at station RER before and during extreme swell events induced by the cyclone Felleng occurring in January 2013 (Fig. 2a) and by an austral swell that hit the island in august 2013 (Fig. 2b). These spectra clearly exhibit the broad and dominating peak of the SMs, the much smaller amplitude peak in the primary frequency band (noted PM) and the presence of a peak of intermediate frequency band (the LPSM) in the case of the austral swell event. Fig. 2 clearly shows that the PM peak is almost absent before the event and develops in the 10-20 s period band during the event. The coincident observation of the PM (around $18 \mathrm{~s}$ in period) and the associated LPSM (around $9 \mathrm{~s}$ in period) is an important indicator of their near coastal generation. Microseismic noise source modelling (Ardhuin et al. 2011, 2012) computed during the maxima of the LPSM observed here reveals that the dominant effect is due to the reflection, confirming the class II nature of the LPSM analysed in this study.

To retrieve continuous information on seismic noise characteristics, we then performed an amplitude analysis to get a proxy for quantifying the significant swell height parameter $H s$. For each seismic station, we performed our measurements on the three seismograph components, corrected by the instrumental response and converted into displacement in microns. We used $1 \mathrm{hr}$ long waveform signals, filtered by a second-order Butterworth bandpass filter with corner frequencies at 0.04 and $0.11 \mathrm{~Hz}$ (i.e. between $\sim 9$ and $25 \mathrm{~s}$ ) for the PM frequency band, at 0.1 and $0.4 \mathrm{~Hz}$ (i.e. $\sim 3$ and $10 \mathrm{~s}$ ) for the SM frequency band, and finally at 0.095 and $0.155 \mathrm{~Hz}$ (i.e. $\sim 6$ and $11 \mathrm{~s}$ ) for the LPSM frequency band. This allows determining the root-mean-square (RMS) of the signal amplitude as function of time in the different frequency bands of the microseisms (Barruol et al. 2006; Davy et al. 2014). The microseismic noise amplitude is finally compared to the swell height parameter $H s$ and may allow determining a transfer function between the microseismic noise and the swell amplitude.
We also performed a polarization analysis of the microseismic noise to quantify the strength and linearity of the polarization and the back-azimuth of the microseismic sources, with the objective of retrieving the localization of the seismic noise sources (for the $\mathrm{SM}$ ) and the swell direction of propagation parameter $D p$ (for the PM). For each hour-long signal window, we quantified the orientation of the ellipsoid characterizing the ground motion. This method is based on a Principal Component Analysis (PCA) that characterizes the 3D (E-W, N-S and Vertical) ground motion (e.g. Barruol et al. 2006; Fontaine et al. 2009). Barruol et al. (2006) described and used this method to characterize swell in French Polynesian islands in the Southern Pacific, which, like La Réunion Island, are subject to strong swell arrivals from the Southern Ocean during the austral winters, from May to September.

\section{CYCLONIC SWELL ANALYSES AT LA RÉUNION ISLAND}

This section is dedicated to the analysis of microseismic noise recorded on La Réunion Island and induced by tropical cyclones that were active in the SW Indian Ocean basin. It has been shown that cyclones in the SW Indian Ocean region generate large microseismic noise in both the PM and the SM frequency band. PM sources are generated in coastal areas by direct interaction of the swell with the sloping sea floor, such as shown by the example of the cyclone Felleng (January 2013) hitting the island of Tromelin located $600 \mathrm{~km}$ NNW of La Réunion (Barruol et al.2016). SM sources are dominantly generated in the deep ocean by standing waves developing mainly in the neighbourhood of storm areas occurring at high latitudes (Stutzmann et al. 2009; Ardhuin et al. 2012), but also in low latitude areas and associated to tropical storms such as demonstrated for cyclone Dumile that occurred in early January 2013 (Davy et al. 2014). Because of the dynamics of the cyclones, interaction between ocean waves of similar periods and opposite directions may occur in various cases: first within the storm system 


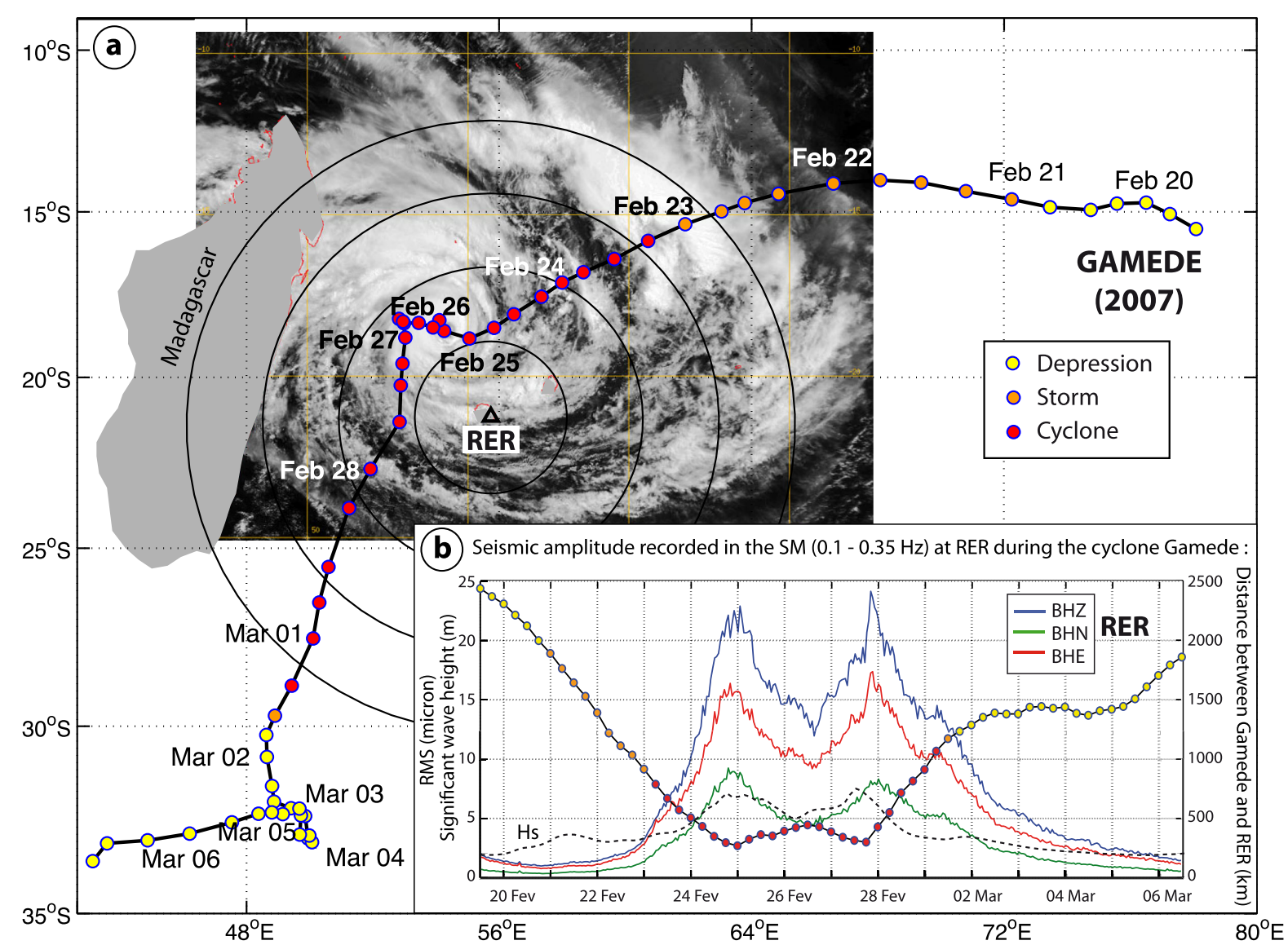

Figure 3. (a) Trajectory and intensity of the cyclone Gamède (February 2007) in the vicinity of La Réunion Island. Meteosat satellite image of Gamède on 2007 February 25 at 06:14 UTC (credits: Météo-France Centre de météorologie spatiale). The four concentric circles indicate the distances of 250, 500,750 and $1000 \mathrm{~km}$ from the RER permanent seismic station (black triangle). (b) RMS of the seismic amplitude in the SM frequency band (0.10-0.35 Hz) recorded at station RER during the passage of the cyclone Gamède (2007). Is indicated the ground displacement on the vertical (blue), NS (green) and EW (red) seismic components (left $y$-axis, in $\mu \mathrm{m}$ ), together with the significant wave height $H s$ (dashed line) predicted west of La Réunion Island by the WaveWatchIII model (left $y$-axis, in meter). The line with the coloured circles indicates both the intensity and the distance between the cyclone Gamède and the RER station (right $y$-axis, in $\mathrm{km}$ ).

or in the trail of the cyclone, where the cyclonic swell generated earlier can interact with the swell generated later. Second, standing waves may also develop by the interaction of the cyclonic swell with its reflected swell on neighbouring coasts (such as Madagascar). Third, cyclonic swell propagating southward may interact with the northward-propagating austral swell and be a source of standing waves. For all these reasons, tropical cyclones can represent a major source of SM.

\subsection{A reference cyclone recorded by the permanent RER station: Gamède (2007)}

We first analysed the SM associated to the cyclone Gamède, which affected La Réunion Island in February 2007. It was selected as a 'reference' event by its strength, duration ( $5 \mathrm{~d})$, trajectory (it approached the island twice in three days) and by its strong impact on La Réunion Island, particularly for the rain since it generated two world records of rain fall in the centre of the island over $72 \mathrm{hr}(3900 \mathrm{~mm})$ and $96 \mathrm{hr}(4900 \mathrm{~mm})(c f$. http://pluiesextremes.meteo.fr), but also for the swell with significant height observed at $7 \mathrm{~m}$ on the north shore and individual waves larger than $10 \mathrm{~m}$ (http://www.cyclonextreme.com). Fig. 3 shows the trajectory and the intensity of the cyclone Gamède in the vicinity of La Réunion, and the hourly RMS of the seismic noise amplitude recorded on the three components of the station RER in the SM frequency band $(0.10-0.35 \mathrm{~Hz})$ during the passage of this cyclone. We observe a clear signal in the SM noise level on the three components, with larger amplitude on the vertical component, which is consistent with the fact that SM is dominantly carried by Rayleigh waves that are vertically polarized. The SM amplitude started increasing as the cyclone was at more than $1000 \mathrm{~km}$ away from La Réunion Island, making the SM useful for cyclone early detection. The variations of the SM amplitude then clearly depends on both the distance and the intensity of the cyclone, with a maximum noise level recorded between February 24 and 28, as Gamède reached the category of intense cyclone and was located at less than $500 \mathrm{~km}$ north of $\mathrm{La}$ Réunion Island. An interesting feature shown in Fig. 3(b) is the gap in the SM energy around February 26, as Gamède reached a peak in intensity in terms of meteorological conditions (see Table 2), and was still quite close to the island. This reduction in the SM amplitude can be explained by the cyclone dynamics. Gamède has had a complex trajectory, which can be decomposed into 4 steps, and that may explain the ' $M$ ' shape of the cyclone signature in the SM band. In the first step (22-25 Feb), Gamède was moving toward the southwest and was becoming more intense and closer to the island. We observed a first peak in amplitude on February 25, synchronous with a first passage of the cyclone centre $250 \mathrm{~km}$ away from the island. In the second step 

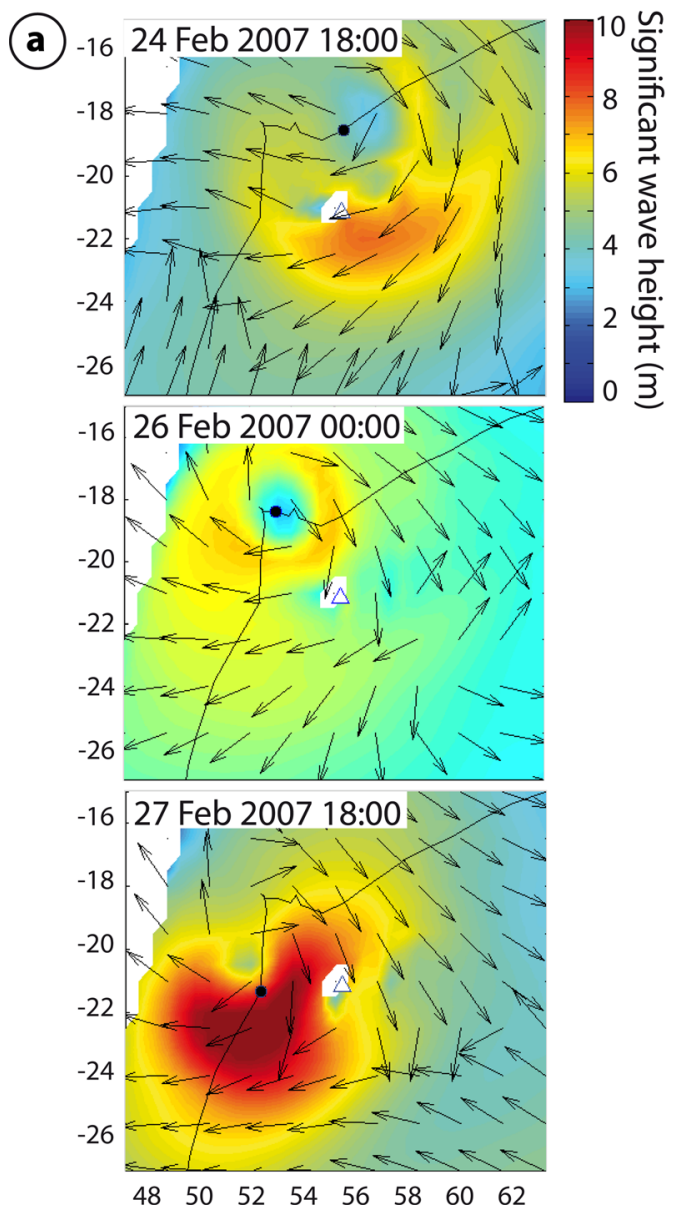

Figure 4. (a) Significant swell height and propagation direction associated to the cyclone Gamède (represented by the black dot along its trajectory), as extracted from the WaveWatchIII model, showing that the highest waves are present on the eastern and southeastern side of the cyclone and a clear swell reduction on Feb. 26 as the cyclone was almost stationary. The RER station on La Réunion Island is represented by the white triangle. (b) Generation of SM explained by the cyclone dynamics. This cartoon shows a cyclone along its trajectory at two different dates T1 and T2. The dangerous semicircle where one observes the highest ocean waves is coloured in pink. The red square gives a possible location for the dominant SM source, where the swell S1 generated in T1 can interact with the swell of similar period and opposite direction S2, generated later in T2 after the cyclone moved.

(25-26 Feb), Gamède changed its trajectory to move toward the northwest. It slowed down and was at a standstill on February 26, which resulted in the decrease in the SM amplitude. In the third step (27-28 Feb) Gamède resumed a stable trajectory southward that revived its dynamics and generated a second peak in the SM amplitude on February 28, synchronous with the second passage close to the island. In the fourth step after February 28, its trajectory changed towards the southwest, Gamède went away from La Réunion and decreased in intensity resulting in a final fall in the SM amplitude.

The schemes presented on Fig. 4 explain how the SM level can be closely linked to the cyclone dynamics. For cyclones in the Southern Hemisphere, winds are blowing clockwise while the cyclones follow a trajectory oriented dominantly southward. The combined effects of the cyclone displacement and the winds directions lead to the generation of the highest ocean waves in the eastern part of the cyclone, called the dangerous semicircle (represented in pink in Fig. 4). When a cyclone moves rapidly along a stable trajectory, the swell $\mathrm{S} 1$ generated at a time $\mathrm{T} 1$ by the cyclone can interact with the swell S2 generated at a later time T2, when the cyclone has moved southward. If the two swells S1 and S2 have similar periods and opposite directions, they may represent a potential source of $\mathrm{SM}$ in the trail of the cyclone (represented by the red square in
Fig. 4). This interpretation is coherent with the ocean waves activity predicted by the WaveWatchIII model during the cyclone Gamède, which is more important when the cyclone is moving along a stable trajectory (Figs 3 or 4). This enables us to relate the SM noise level with the cyclone dynamics.

\subsection{Cyclone-related seismic noise recorded by a seismological network in La Réunion: the SM band}

To investigate the cyclone-induced seismic noise recorded on La Réunion, and particularly the spatial and temporal variations, we used ten seismic stations of a temporary network that were deployed on the island between 2012 and 2015 in the frame of the RHUM-RUM project (Barruol \& Sigloch 2013). We performed a systematic analysis of the seismic noise induced by the tropical cyclones Dumile (January 2013), Felleng (January 2013) and Bejisa (January 2014), in both the PM and the SM frequency bands. Fig. 5 shows the trajectories and intensities of these cyclones in the vicinity of La Réunion Island, with the position of the storm centres provided on a $6 \mathrm{hr}$ basis by Météo France. All these cyclones passed by La Réunion at sea from north to south, west of the island. The centre of the tropical cyclones Dumile and Bejisa passed close to the western coast of La Réunion, at 160 and $90 \mathrm{~km}$, respectively. 


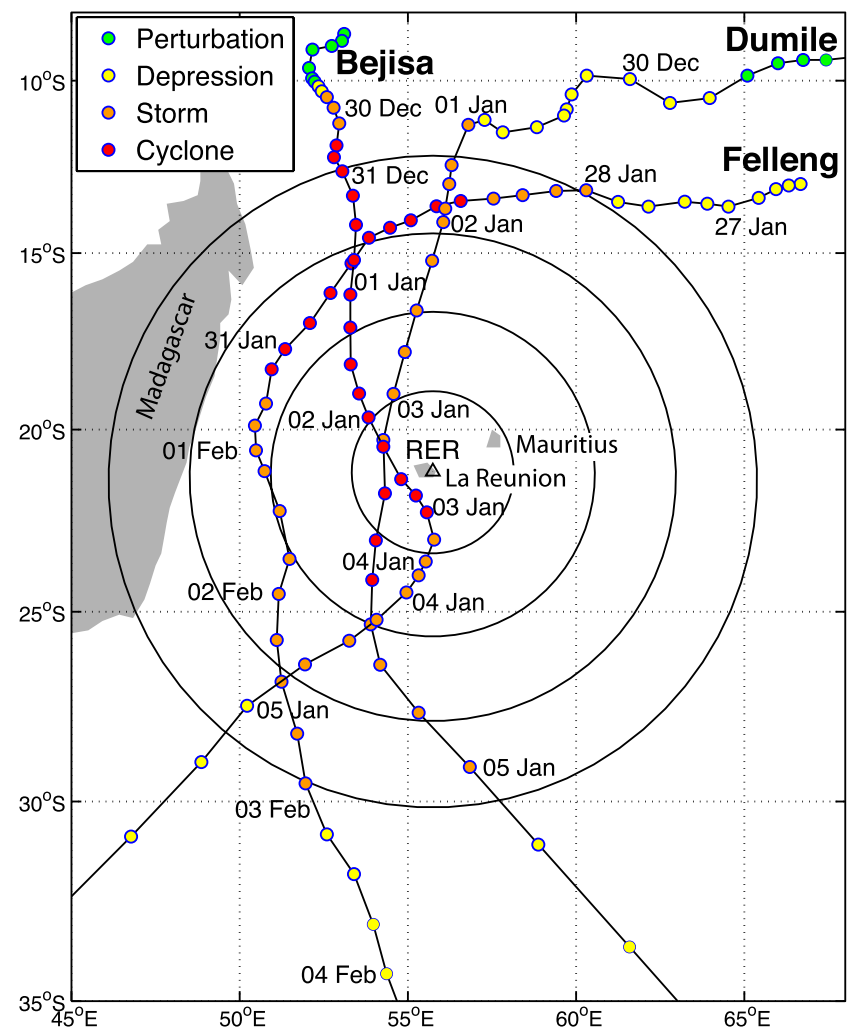

Figure 5. Trajectories and intensities of the tropical cyclones Dumile (December 2012 to January 2013), Felleng (January 2013) and Bejisa (December 2013 to January 2014) in the vicinity of La Réunion Island. The circles on each trajectory indicate the position of the storm centre on a $6 \mathrm{hr}$ basis by Météo-France Réunion and the circle colour the intensity of the meteor, following the colour code detailed in the top left window. The four concentric circles indicate the distances of 250, 500, 750 and $1000 \mathrm{~km}$ from the RER permanent seismic station, indicated by the black triangle on La Réunion Island.

Meteorological data on all the tropical cyclones analysed in this study are detailed in Table 2 and show that the cyclones considered in this study are characterized by different strengths, as seen by the minimum pressure in the cyclone centre and by the average wind speed.

Fig. 6 evidences that all the stations on La Réunion Island recorded an extremely coherent signal in the SM frequency band, despite differences in amplitudes between stations. For each cyclone, SM amplitude follows very similar patterns of variations from station to station. We observed a slightly lower noise level at the stations MAID and SALA, which are located in the internal region of the island.

These continuous measurements clearly show that each cyclone has its own signature depending on its dynamics, strength and distance to the island. Dumile and Bejisa, which followed a similar trajectory near La Réunion, generated the same level of noise, with a maximum around $13 \mu \mathrm{m}$ at the station STPI, and the shape of their SM patterns are very similar, with a pronounced peak when the cyclones were very close to the island. For the cyclone Dumile, we note a second peak with smaller amplitude in the SM occurring on January 5. This peak is not related to SM generated by the cyclone itself but probably to a class III SM noise source, likely resulting from the interaction between the cyclonic swell and an austral swell event arriving at this period (not shown here). The WaveWatchIII hindcast model shows indeed that an austral swell propagating from southwest to northeast met the cyclonic swell issued from Dumile with an opposite direction on the 5 January at $06 \mathrm{hr}$ UTC. Interactions between these two swells may explain the second peak observed at this date in the SM recorded at the stations, by the generation of a class III SM noise source located more than $1600 \mathrm{~km}$ southwest of La Réunion.

Despite the cyclone Felleng passed at a larger distance from La Réunion, it generated larger SM amplitude, with a maximum of $19 \mu \mathrm{m}$ measured at the southernmost station STPI. The overall pattern of its signal is characterized by a high noise plateau and two dominating peaks. According to meteorological observations, Felleng was particularly large in size and characterized by more powerful winds, in comparison with Dumile and Bejisa (see Table 2). As a consequence, Felleng generated ocean wave activity on a larger zone, with an efficient generation of SM. It can also be noted that the SM amplitude is proportional to the square of the ocean wave height (Longuet-Higgins 1952), which are controlled, among others, by the wind speed. This may explain why the cyclone Felleng is characterized by higher noise level amplitude in the SM (see Table 2).

In summary, this analysis of the cyclone-related seismic noise shows that the SM carries relevant information on both the distance and the intensity of the cyclone, but also on its trajectory and dynamics. At a local scale of few tenths of $\mathrm{km}$, the signature observed on La Réunion Island is extremely homogeneous for a given cyclone, indicating that all the stations are primarily affected by a common distant source. The small observed variations in SM amplitudes across the network are likely induced by a combination of the station distance to the coast and to other local effects.

\subsection{Cyclone-related seismic noise recorded by a seismological network in La Réunion: the PM band}

Most cyclones develop north-south trajectories in the neighbourhood of La Réunion Island (see Fig. 5 and http://www. meteofrance.re/cyclone/saisons-passees/). Since the cyclonic swell propagates mainly in the direction of the cyclone's trajectory, it usually impacts the northeast and the northwest coasts of La Réunion, generating local seismic noise sources of PM. Fig. 7 shows the PM signals recorded by the seismic stations in the $0.07-0.18 \mathrm{~Hz}$ frequency band (5.5-14.0 s of period), together with the significant wave height $H s$ measured by the buoy RN4 located close to the north shore of La Réunion (see Fig. 1). We analysed the PM signal in this particularly high frequency band because the cyclonic swell is generally characterized by shorter periods than the austral swell (e.g. around $7 \mathrm{~s}$ in period). Thus, we find the best fit between the significant wave heights $H s$ measured by the buoy RN4 and the PM noise amplitude in this frequency band, at least during the first period of each record, when the swell was impacting the island. However, the high microseismic amplitude reached in this frequency band suggests that part of the signal is clearly dominated by SMs too. The second peak evidenced on each record (while no ocean waves are observed locally) are therefore probably dominated by SMs of class I or III, which can be generated by the cyclone dynamics itself or by the interaction between the cyclonic swell propagating SW with austral swell of similar period and opposite direction. Such last case may lead to the generation of a distant source of SM located at more than $1000 \mathrm{~km}$ southwest of La Réunion, generally a few days after the cyclone passed the island.

According to the meteorological observations, the swell from NE generated by the cyclone Dumile reinforced at the end of the 2013 


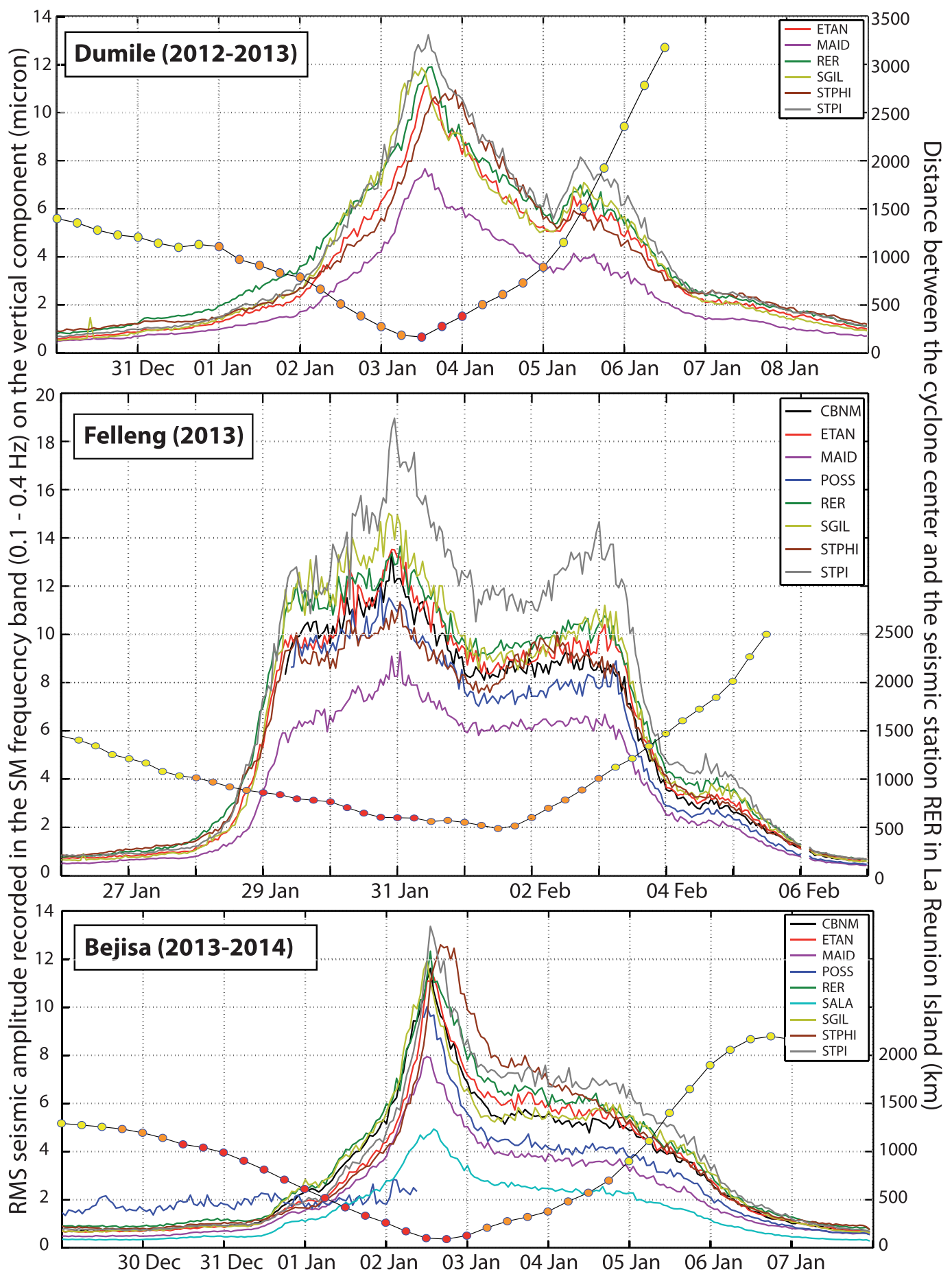

Figure 6. RMS of the seismic noise amplitude recorded in the SM frequency band (0.1-0.4 Hz, i.e. $2.5-10.0 \mathrm{~s}$ of period) on the vertical component of the seismic stations in La Réunion during the passage of the tropical cyclones Dumile, Felleng and Bejisa. The distance between the cyclones and the seismic station RER (in km on the right $y$-axis) is given by the lines with the coloured circles, which indicate the intensity of the cyclones with the colour code used in Fig. 3. For interpretation see the text.

January 2nd and the following night during the intensification of Dumile (Fig. 7). The swell impacted predominantly the northeast, the north and the northwest coasts of La Réunion, and got its paroxysm on January 3rd at midday, coming from the north. The highest ocean waves were recorded at La Pointe du Gouffre (Fig. 1) with a maximal height of $11 \mathrm{~m}$ and a significant wave height of $6.3 \mathrm{~m}$. With the rapid evacuation of the cyclone southward, the swell started to decrease the 4th January and clearly weaken on the 5th January.
The cyclone Felleng passed $500 \mathrm{~km}$ west off La Réunion and had logically less impact on the island. The swell from NW and then from W impacted the coasts on 2013 January 31st, with a significant wave height of $3.8 \mathrm{~m}$ measured at Port-Est at $20 \mathrm{hr}$ UTC and a maximal height of $7.2 \mathrm{~m}$, which is indeed much less than the two other analysed cyclones. Interestingly, we record high seismic noise level during the cyclone Felleng (up to $16 \mu \mathrm{m}$, Fig. 7). This likely due to the large spectra of the ocean waves period 

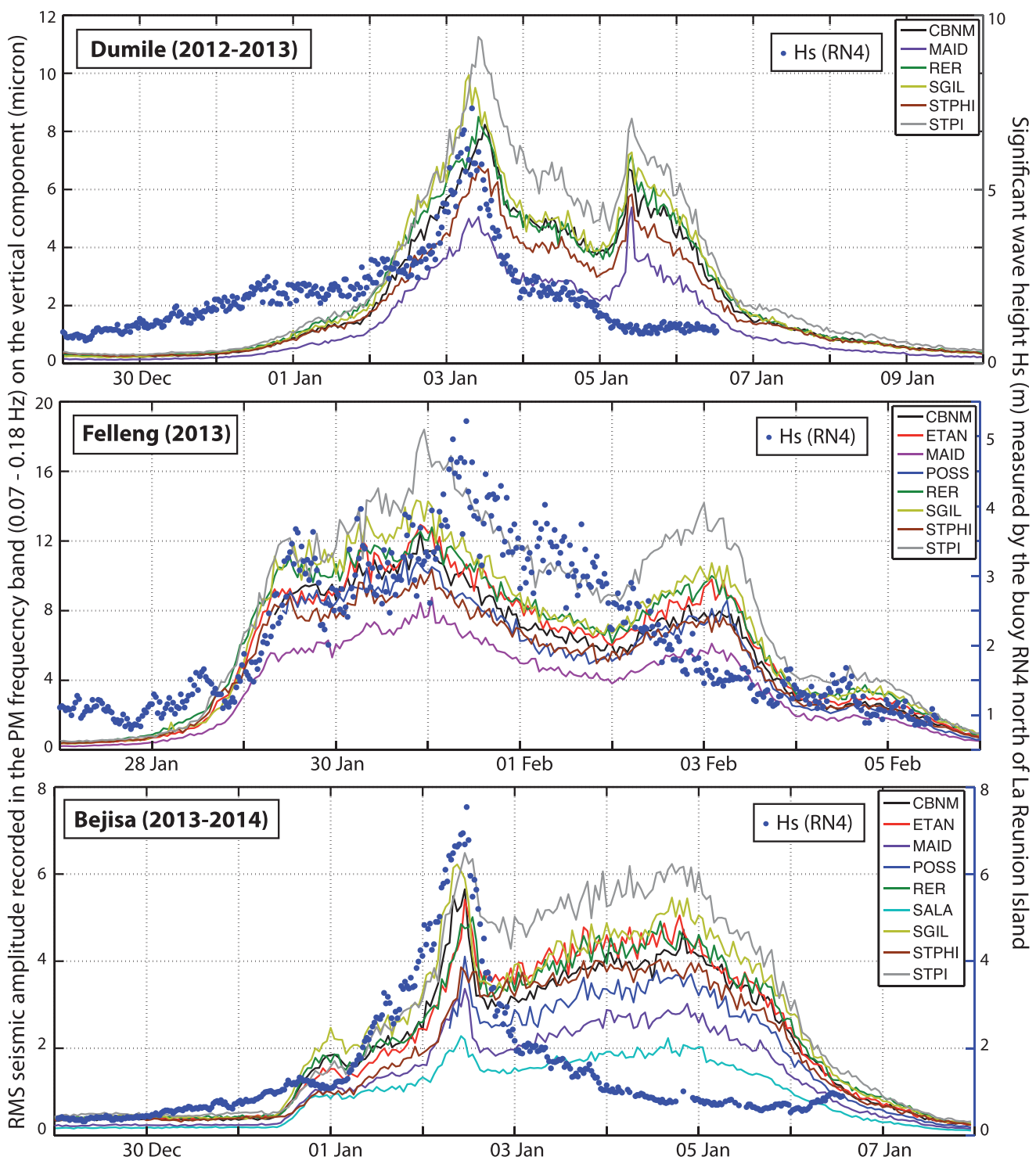

Figure 7. RMS of the seismic noise amplitude recorded in the PM frequency band (0.07-0.18 Hz, i.e. 5.5-14.0 s of period) on the vertical component of the seismic stations on La Réunion during the passage of the tropical cyclones Dumile, Felleng and Bejisa. The blue dots represent the significant wave height (Hs, in $\mathrm{m}$ on the right $y$-axis) measured at sea by the buoy RN4 located north of La Réunion (see location Fig. 1). For interpretation, see the text.

generated within a cyclone, since the selected frequency band between $0.07-0.18 \mathrm{~Hz}$ contains mostly PM but may also includes part of the SM signal. We observe, however, an overall good correlation between the PM amplitude and the significant wave height during this cyclone.

The cyclone Bejisa followed a similar trajectory than Dumile but passed closer to La Réunion, at $10 \mathrm{~km}$ only from Saint-Gilles on the 2014 January 2nd in the afternoon, and with a larger intensity (see Fig. 5 and Table 2). The swell impacted the island from January 1 to 4 and the maximal waves heights were of 10 and $11 \mathrm{~m}$ on the north and northwest coasts. We find a particularly good correlation between the PM amplitude recorded at SGIL (in yellow on Fig. 7) and the significant wave height recorded at RN4 during the cyclones Dumile and Bejisa when the swell was impacting the island from its northern side, with correlation factors of 0.93 and 0.96 respectively. Interestingly, for both cyclones, the good correlation between the microseismic noise and the buoy-derived swell height is then lost as the cyclone centre was located south of the island. This can be explained by the fact that the buoy is installed on the north shore and become then protected from the northward-propagating swells.

\section{AUSTRAL SWELL SIGNATURES AT LA RÉUNION ISLAND}

This section is dedicated to the analysis of microseismic noise recorded on La Réunion Island during austral swell events. This kind of swell, generated at large distances in the southern Indian Ocean basin, has generally significant wave height smaller than the cyclonic swell but longer wave period as it reachs La Réunion, and it can have larger consequences on some sites directly exposed to its impact. Because of its energy, it is particularly erosive and can also cause important coastal submersions and may have strong influence on reef dynamics (Cordier et al. 2012). On the other hand, the ocean swell, as a sustainable energy, represents a huge potential resource to produce electricity that could participate in the energy autonomy of the island and therefore deserve to be accurately quantified at the scale of the island. 

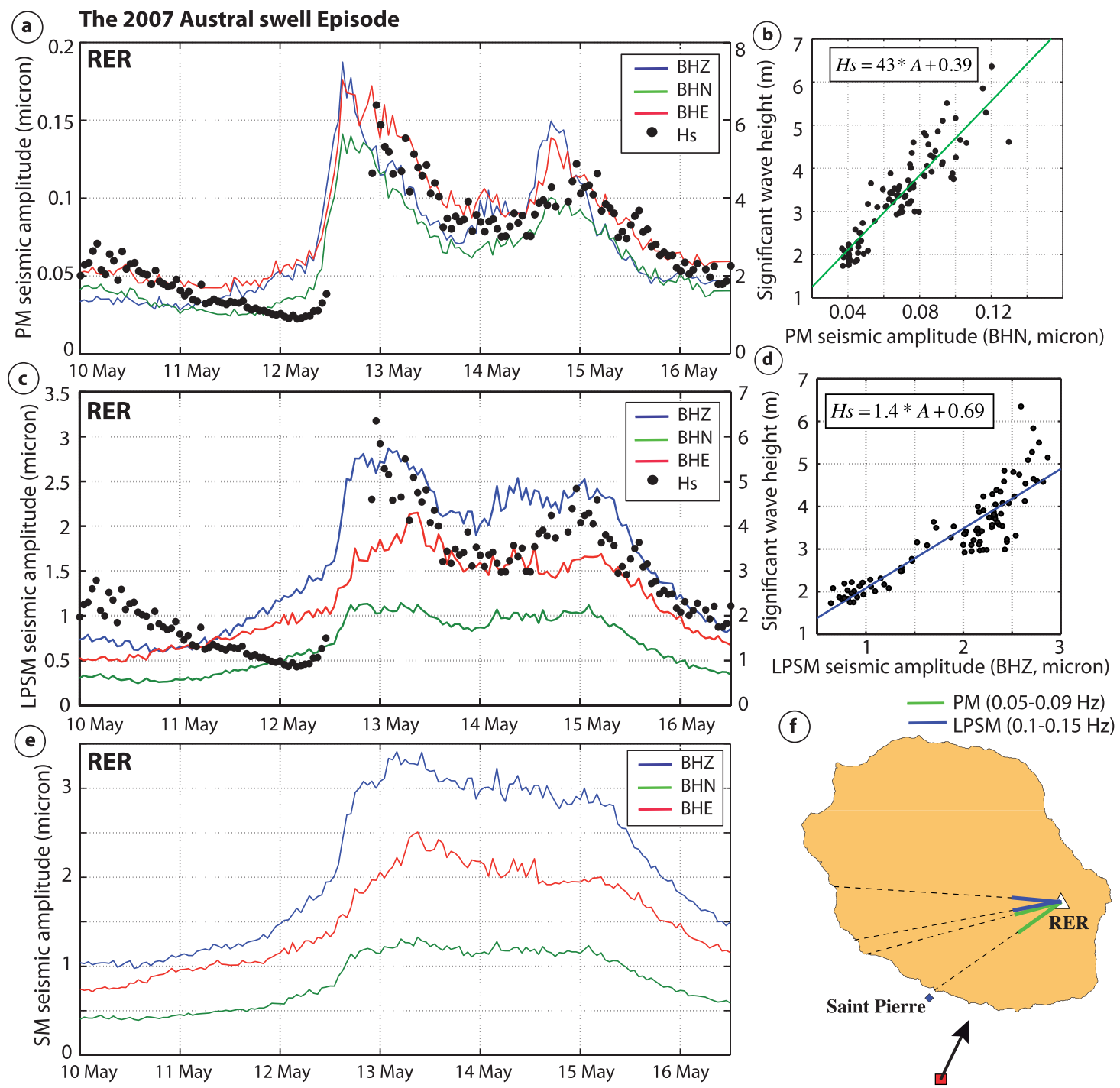

Figure 8. RMS of the seismic noise amplitude (in $\mu \mathrm{m}$ on the left $y$-axis) recorded during the May 2007 austral swell event on the three components of the station RER in different frequency bands: (a) PM $(0.05-0.09 \mathrm{~Hz}$, i.e. $11-20$ s period), (c) LPSM $(0.10-0.15 \mathrm{~Hz}$, i.e. $6.6-10.0 \mathrm{~s}$ period), (e) SM (0.10-0.35 Hz, i.e. $2.8-10.0 \mathrm{~s}$ period), with the significant wave height (black dot, in $\mathrm{m}$ on the right $y$-axis) measured on the ocean wave gauge located near Saint-Pierre. Note the absence of data during the main swell peak due to technical failure. $(b, d)$ Transfer functions determined from the significant wave height and the seismic amplitude in the PM (north component) and the LPSM (vertical component) frequency bands, respectively. (f) Map of La Réunion Island with the azimuth of the PM (in green) and the LPSM (in blue) seismic noise measured by polarization analysis at the station RER during the main peak of the May 2007 austral swell event.

\subsection{A reference austral swell recorded by RER station: the May 2007 Episode}

A particularly strong swell event hit La Réunion in May 2007, with two main swell peaks that impacted the island on May 12th and 14 th at night. The significant wave heights were close to $6 \mathrm{~m}$ at sea and longer swell periods around 14-16 s. The swell breaking on the western and the southern coasts caused the death of two fishermen and important damages in the harbours of Saint-Gilles, Saint-Leu and Saint-Pierre.

Noise spectra computed at the station RER during this event (not shown here) clearly show a PM peak with the same periods of the swell (between 11 and $20 \mathrm{~s}$ ) and a LPSM peak with periods twice shorter (between 6.5 and $10 \mathrm{~s}$ ), that we interpret as a local source of class II SMs, which result from the interaction between the incident swell and the ocean waves of similar periods reflected off the shore.
Fig. 8(a) compares the measured variations in amplitude of the seismic noise recorded on the three components at station RER, filtered in the PM frequency band $(0.05-0.09 \mathrm{~Hz}$, i.e. between 11 and $20 \mathrm{~s}$ of period) with the significant wave height measured at the ocean wave gauge that was located offshore near Saint-Pierre at that time (Fig. 1). The observed direct correlation between $H_{s}$ and the seismic noise amplitude in the PM frequency band suggests that a simple law can be deduced, relating almost linearly the seismic noise amplitude to the swell height. We find the highest correlation factor of 0.91 between the seismic noise amplitude $A$ (in $\mu \mathrm{m})$ recorded on the north component of the seismometer and the significant wave heights $H s$ (in m) computed between 13-16 May. Fig. 8(b) shows such relation between the PM amplitude recorded at station RER on the north component and the significant wave heights $H s$ measured at Saint-Pierre for this swell event of May 2007: each point represents the hourly RMS of the microseismic 
noise amplitude at a given time with the corresponding $H_{s}$ value. The best estimate of a transfer function relating these two parameters is the linear relationship $H s=43 * A+0.39, H s$ in $\mathrm{m}$ and $A$ in $\mu \mathrm{m}$. This example indicates that measurement of the microseismic noise amplitude can provide a good proxy for swell height, and can be used to get precious swell data, particularly in remote and poorly instrumented areas, or in case of failures of oceanographic instruments during extreme swell events, as occurred at the wave gauge of Saint-Pierre during the first swell peak on 2007 May 12 (Fig. 8a).

Fig. 8(c) compares the evolution of the seismic noise amplitude filtered in the LPSM frequency band $(0.10-0.15 \mathrm{~Hz}$, i.e. between 6 and $10 \mathrm{~s}$ of period), with the significant wave heights measured at the ocean wave gauge located offshore near Saint-Pierre. Seismic noise in the LPSM frequency band is recorded with larger amplitude, particularly on the vertical component that reached a maximum of $3 \mu \mathrm{m}$ on May 13 at $2 \mathrm{hr}$ UTC. We observe that the seismic amplitude in the LPSM frequency band becomes important on May 12 in the afternoon, as the swell impacted La Réunion Island, suggesting that the source of LPSM was located close to the shore. Such peak of energy likely corresponds to a class II of SMs, which result from the interaction between incident ocean waves and the ones reflected off the shore with similar periods. The $H s$-LPSM amplitude relation shown on Fig. 8(d) and computed between May 13 and 16 displays a correlation factor of 0.9 . The best estimate of a transfer function relating these two parameters is the linear relationship $H s=1.4 * A+0.69$ ( $H s$ in $\mathrm{m}, A$ in $\mu \mathrm{m})$.

Fig. 8(e) shows the seismic noise amplitude filtered in the larger SM frequency band $(0.10-0.35 \mathrm{~Hz}$, i.e. between 3 and $10 \mathrm{~s}$ of period). One observes that the SM amplitude is of the same order than the LPSM and much larger than the PM amplitude. The dominant noise source in the secondary band seems to be carried by the LPSM and therefore, by sources of class II (stationary waves in the vicinity of the coast, generated by swell reflection) during this event. We showed that transfer functions can be used to estimate the swell height from the seismic noise amplitude recorded in the PM or in the LPSM frequency bands (Figs 8b-d), but it is also possible to retrieve the swell direction from the azimuth of the seismic noise. The polarization analysis performed on the PM seismic noise gives an azimuth included between $\mathrm{N} 235^{\circ}$ and $\mathrm{N} 255^{\circ}$ during the main swell peak (in green on Fig. 8f), that points toward the southwest coast of the island, from the local areas of 'Pointe du diable' to 'Pointe de l'Etang Salé'. A similar result is given by the global wave model WaveWatchIII, showing a swell propagating in the azimuth $\mathrm{N} 027^{\circ} \mathrm{E}$ (black arrow in Fig. 8f), that impacted the southern and western coasts of La Réunion. The azimuths measured by the polarization analysis of the LPSM noise range between $\mathrm{N} 260^{\circ}$ and $\mathrm{N} 275^{\circ}$ (in blue on the Fig. 8f) point a source region off the western coast between the areas 'Pointe des Avirons' and 'Pointe des châteaux' (see locations in Fig. 1). The noise spectra show that LPSM develop simultaneously with the PM, suggesting that the LPSM sources are close to the shore but our analysis cannot provide their exact distance to the shore.

This May 2007 reference event shows that it is possible to quantify an extreme swell event via its signature in the seismic noise in terms of amplitude (by the elaboration of a transfer function), of direction (by a polarization analysis) and of period (by computing noise spectra). For this austral swell event, the dominant PM noise source is probably located on the southwest coast, which is frontally impacted by the swell.
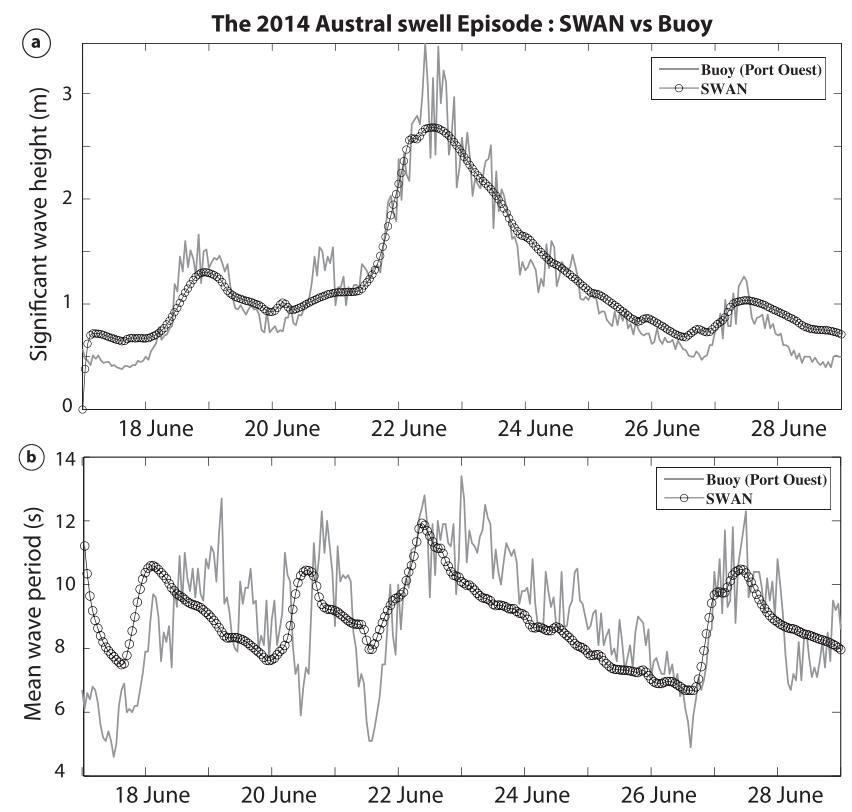

Figure 9. Comparisons between the Port Ouest (located Fig. 1) buoy observations (grey line) and the local predictions from the SWAN model (black circles) for the significant wave height $H_{s}$ (a) and the mean wave period $T p$ (b) during the 2014 austral swell event. See the text for details.

\subsection{Austral swell-related seismic noise recorded by a seismological network in La Réunion}

During the RHUM-RUM experiment, the seismological network deployed on La Réunion recorded several large austral swell events, two of them being extreme in the significant wave height: the first occurring in August 2013 and the second in June 2014. Because no ocean waves gauge was available on the southern and the western coasts of the island, we used a local ocean wave model SWAN to get the significant wave height parameter $H s$ together with the mean wave period $T p$ at different points located around the island near the seismic stations locations (Fig. 1). SWAN is a third-generation wave model developed at Delft University of Technology that computes random, short-crested wind-generated waves in coastal regions. The model is based on the wave action balance equation with sources and sinks. See Booij et al. (1999) for a detailed description. The model was run for two weeks around each swell events of August 2013 and June 2014, using boundaries forcing from the hindcast runs of the global wave model WaveWatchIII, and wind fields provided by ECMWF (European Centre for Medium-Range Weather Forecasts) as surface forcing. The interest of using a local model with a higher resolution of $0.004^{\circ}(\sim 500 \mathrm{~m})$ is to better model the local impact of the swell on the different coasts of the island and to select grid point in the vicinity of each seismic stations (green squares on Fig. 1). Those grid points in the vicinity of each seismic station have been chosen in function of their depth so that a swell of wavelength $\lambda$ starts to interact with the seafloor, that is to say approximately $\lambda / 2$. We determined the reliability of this local hindcast by comparing the modelled significant wave height $H_{s}$ with the ocean wave gauge measurements located at the Port Ouest (Fig. 9a). We found a correlation coefficient of 0.91 for the swell event of 2013 (and of 0.95 for the 2014 swell, shown on Fig. 9), with a bias of $-0.21 \mathrm{~m}$ (of $-0.11 \mathrm{~m}$ for the 2014 swell), a root-mean-square-error RMSE of $0.33 \mathrm{~m}(0.23 \mathrm{~m}$ for 2014$)$ and a scatter index of $0.40(0.20$ for 2014). These results allow us to validate the local hindcast runs, 
(a) The 2013 Austral swell Episode

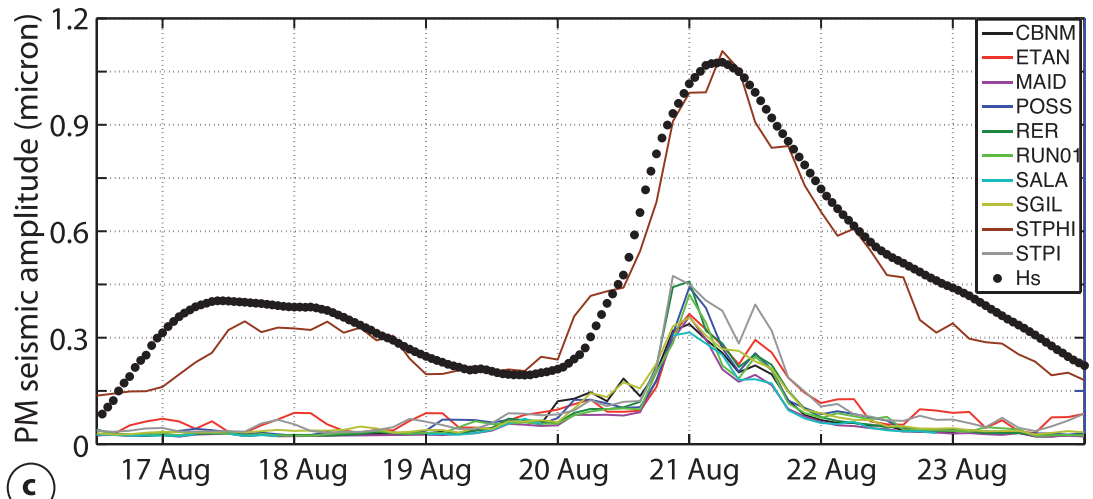

(c) 17 Aug 18 Aug 19 Aug 20 Aug 21 Aug 22 Aug 23 Aug
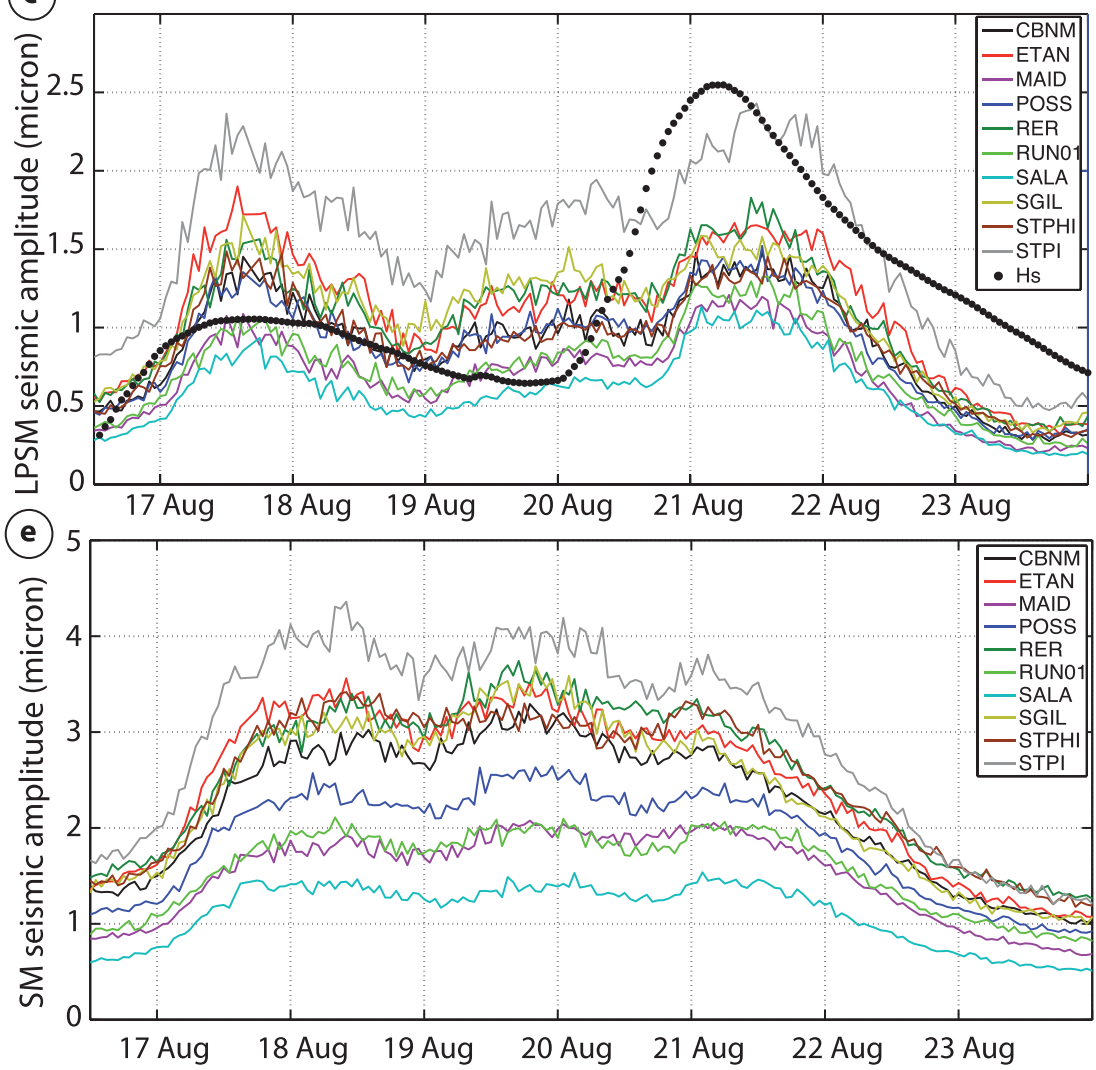

(b)

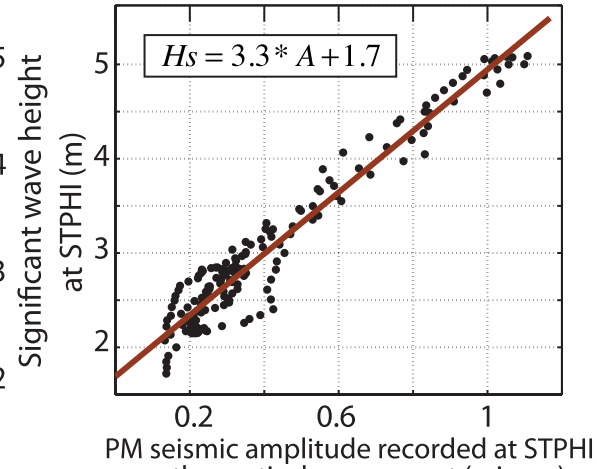

(d)
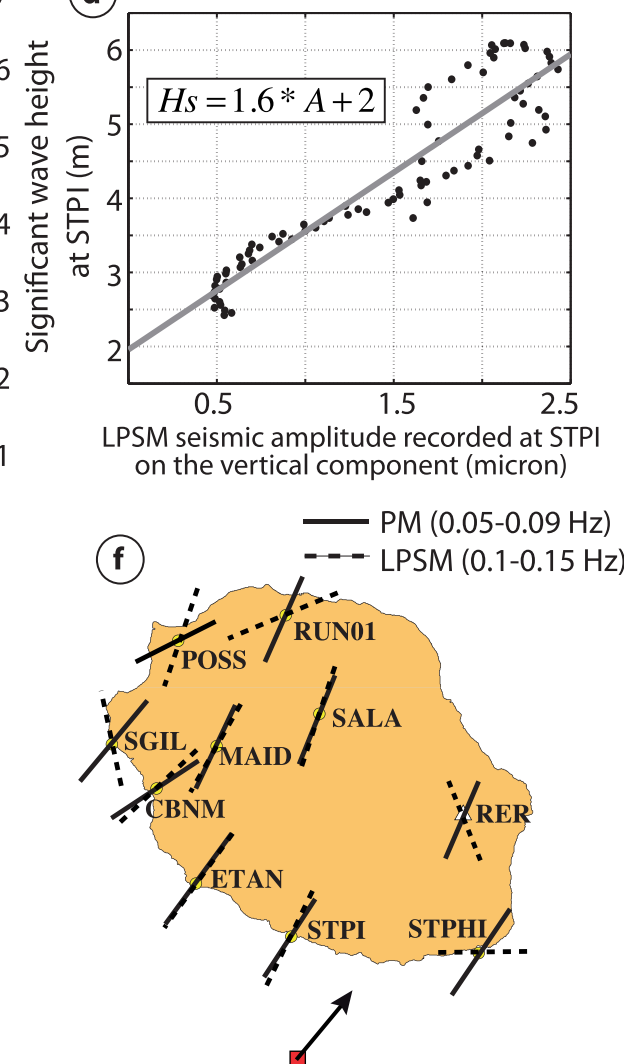

Figure 10. RMS of the seismic noise amplitude (in $\mu \mathrm{m}$ on the left $y$-axis) recorded on the vertical component of the RHUM-RUM seismic stations in different frequency bands: (a) PM (0.05-0.09 Hz, i.e. 11-20 s period), (c) LPSM $(0.10-0.15 \mathrm{~Hz}$, i.e. 6.6-10 s period), (e) SM (0.10-0.35 Hz, i.e. $2.8-10$ s period) during the August 2013 swell event, together with the significant wave height (black dots, in $\mathrm{m}$ on the right $y$-axis) determined from the local numerical wave model SWAN, using a grid node near Saint-Philippe station STPHI (a) and Saint-Pierre station STPI (c). (b-d) Transfer functions between the significant wave height $H s$ and the seismic amplitude recorded on the vertical component in the PM (at STPHI) and the LPSM (at STPI) frequency bands, respectively. (f) Map of La Réunion Island with the azimuth of the PM (black line) and the LPSM (dotted line) measured by polarization analysis on the RHUM-RUM seismic stations during the main peak of the August 2013 swell event. The swell propagation direction $D p$ is indicated by the arrow.

with a slightly better score for the swell event of June 2014 (Fig. 9). The comparison of the dominant wave period $T p$ determined from SWAN modelling with the observations from the Port-Ouest buoy displays also a good correlation (Fig. 9b), suggesting that both the modelled wave amplitudes and periods can be confidently used in the seismological analysis.

Fig. 10(a) shows the seismic amplitude recorded in the PM frequency band on the vertical component of all the seismic stations with data available during the August 2013 event, together with the significant wave height parameter $H s$ computed by the SWAN model at the node close to station STPHI. The noise level recorded in the PM frequency band is clearly much higher at the STPHI seismic station, which is located in the southeast extremity of La Réunion Island (Fig. 1). The maximum noise amplitude recorded at STPHI reached $1 \mu \mathrm{m}$ as the austral swell hit the island on August 21, whereas the other stations recorded a signal with amplitude included between 0.30 and $0.45 \mu \mathrm{m}$. That can be explained by the geographical position of the station STPHI located very close to the rocky shore (see Table 1), that efficiently transfers the PM wave energy into the ground by a particularly efficient transfer function. 
The presence of basaltic cliffs along the southern and eastern coasts is likely to provide a good coupling for an optimal PM signal propagation to the station, in comparison with slowly dipping shores or with the lagoon area along the western part of the island that apparently provide a less efficient coupling and energy transportation to the seismic sensor.

We find a high correlation factor of 0.97 between the PM seismic noise recorded on the vertical component of the station STPHI and the significant wave heights $H s$ modelled by the local SWAN model near the station (black dots, Fig. 10a), suggesting a particularly robust proxy for using this seismic station as a wave gauge. Fig. 10(b) shows the linear relation between these two parameters, with the best estimate given by the relationship $H s=3.3 * A+1.7$.

In comparison, Figs 10(c) and (e) show the seismic noise recorded during the same swell event in the LPSM and the SM frequency band, respectively. The SM noise is recorded with larger amplitude for the stations located on the southern and the western coasts of $\mathrm{La}$ Réunion, whereas the noise level is smaller and seems attenuated for the stations located on the northern coast or inland. Interestingly, we clearly observe that the SM noise level starts increasing on august 17 , that is to say $4 \mathrm{~d}$ before the austral swell hit the island. This is a clear example of a distant source of SMs of class I, generated in deep ocean by interactions between ocean waves with similar periods and opposite directions, within a storm located more than a thousand $\mathrm{km}$ away, southwest of La Réunion. All the conditions needed to develop high-amplitude and long period ocean waves are found in the deep austral depressions: high wind speed with long fetch and duration of generation. Due to the very large spreading of the austral swell, in comparison with the size of the island, La Réunion is frequently hit by these extreme swell events. In this case, the SM increase recorded on the island can be considered as a warning and precursor of the swell generated by the storm, which takes usually about 3-4 d to propagate northeastwards before reaching $\mathrm{La}$ Réunion Island. The source of this noise is located in the southern Ocean, as demonstrated by Davy et al. (2015) from the analysis of permanent seismic stations located in the Indian Ocean and also modelled from wave dynamics (Ardhuin et al. 2011; Stutzmann et al. 2012). This particular swell event was recently analysed at the seismic stations located in the Mozambique channels (Barruol et al. 2016) and the map of this swell propagation in the SW Indian Ocean was presented in their Fig. 3. We also observe a clear LPSM signal recorded on August 21, when the swell hit the island. That clearly favours a local source of class II SMs, resulting from the interactions between the incident austral waves and the reflected waves of similar period off the shore. We find a correlation factor of 0.93 computed between the LPSM noise at station STPI and the significant wave heights computed by the SWAN model near the station, from 20 to 24 August. Fig. 10(d) shows the linear relation between these two parameters, with the best estimate given by the relationship $H s=1.6 * A+2$.

The polarization computed in the PM frequency band for all these stations give a PM seismic noise back-azimuth that points toward the southwest, with a clear parallelism between the swell propagation direction $D p$ (about $\mathrm{N} 040^{\circ} \mathrm{E}$, as determined by WaveWatchIII models) and the azimuth of the ground polarization, showing that the swell direction may be confidently retrieved on land from seismic polarization analysis (Fig. 10f). The azimuths computed from the polarization analyses in the LPSM frequency band for all the stations show also a rather good parallelism with the swell propagation direction. They mostly point toward the southwest (Fig. 10f), where the shore impacted frontally by the austral swell allowed an efficient ocean waves reflection.
In the same way, Fig. 11 shows the seismic noise levels recorded by the RHUM-RUM and GEOSCOPE stations during an episode of extreme austral swell that hit La Réunion in June 2014. Once again, the PM amplitude recorded at STPHI station is much larger than at the other stations and can be used to monitor the local ocean waves activity with a good resolution. We determined a correlation factor of 0.92 between the PM seismic noise recorded on the vertical component of the station STPHI and the significant wave heights $H_{s}$ computed by the local SWAN model near this station (Fig. 11a). The best estimate for the linear relationship linking these two parameters is given by $H s=3.5 * A+1.5$, which is very close to the one found for the August 2013 case, suggesting that this transfer function is robust and fits equally well for the austral swell events (Fig. 11b).

Figs 11(c) and (e) show the seismic noise recorded during this event of June 2014 in the LPSM and the SM frequency band, respectively. The SM noise level became important on June 22, as the swell was already impacting the island, suggesting in this case a dominant source of SMs of class II, resulting from the reflection of the incident ocean waves on the shore. We find a correlation factor of 0.92 between the LPSM noise amplitude at station STPI and the significant wave heights computed by the SWAN model near the station for this event. Fig. 11(d) shows the roughly linear relation between these two parameters, with the best estimate given by the relationship $H s=1.3 * A+1.2$. Once again, the similarity of the transfer functions determined for the austral swell events of 2013 and 2014 suggests that the LPSM amplitude measured at the STPI station can be confidently used to quantify the ocean wave activity during the extreme austral swells that hit La Réunion and can be reflected off the southwest coast of the island.

The results of the polarization analysis computed for all the stations in the PM frequency band during the main swell peak for this June 2014 event still indicate azimuths that point toward the southwest, that is, parallel to the incoming swell propagating along $\mathrm{N} 035^{\circ} \mathrm{E}$ azimuth, as predicted by the ocean waves models south of La Réunion. This indicates a dominant source of PM along the coast, where the austral swell hit frontally the island (Fig. 11f). Such observations also suggest that the swell-shore interaction induces ground motions with a preferred orientation parallel to the swell propagation direction, as already described from PM analyses in French Polynesia islands in the South Pacific Ocean (Barruol et al. 2006) and emphasize the possibility of retrieving the swell propagation direction $D p$ from microseismic noise recorded by terrestrial stations.

\section{CONCLUSIONS}

Seismic data recorded on oceanic islands such as La Réunion can be used to analyse and quantify the swell activity through its signature in the microseismic noise. We found that tropical cyclones represent a major source of SM, which are generated by the interaction of ocean waves with similar periods and opposite propagation directions. We showed that SM can be used for cyclones detection and monitoring, since they can be recorded on-land, as far as $1000 \mathrm{~km}$ away and since they contain relevant information on their distances and intensities, as well as on their dynamics and trajectories. Major storms occurring in the southern part of the Indian ocean can also generate distant sources of SM that may be recorded almost instantaneously on-land by seismic stations and that can be used to forecast the potential swell impact a few days in advance. 
(a)

동
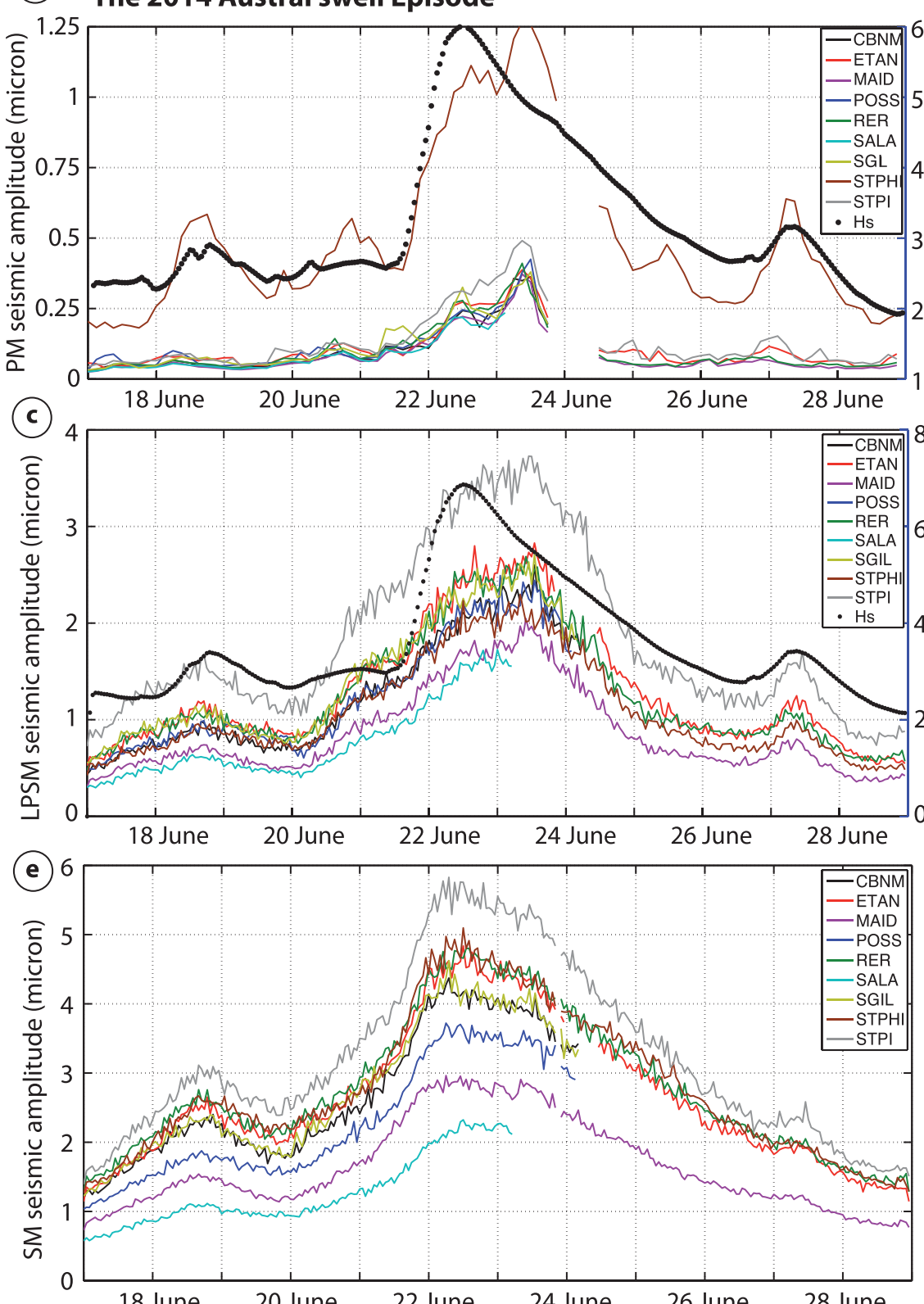

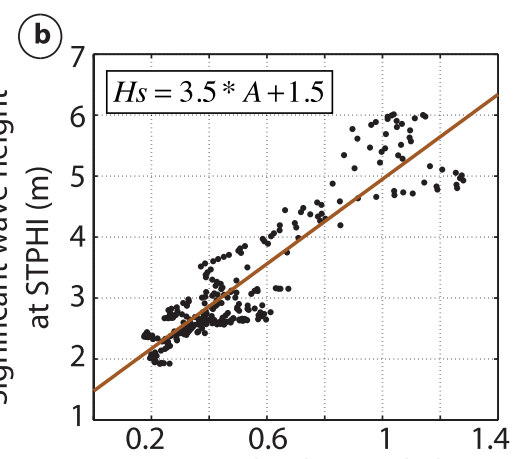

PM seismic amplitude recorded at STPHI on the vertical component (micron)

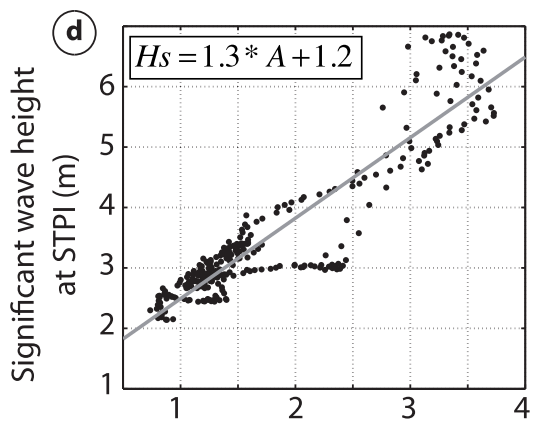

LPSM seismic amplitude recorded at STP on the vertical component (micron)

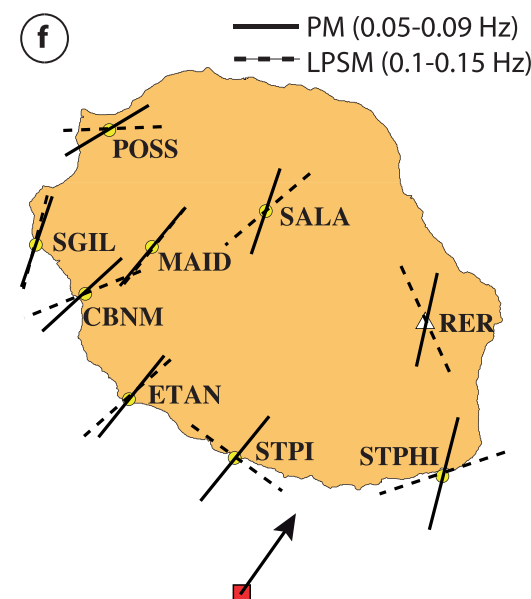

Figure 11. RMS of the seismic noise amplitude (in $\mu \mathrm{m}$ on the left $y$-axis) recorded on the vertical component of the RHUM-RUM seismic stations in the frequency bands: (a) PM $(0.05-0.09 \mathrm{~Hz})$, (c) LPSM $(0.10-0.15 \mathrm{~Hz})$, (e) SM $(0.10-0.35 \mathrm{~Hz})$ during the June 2014 swell event, with the significant wave height (black dots, in $\mathrm{m}$ on the right $y$-axis) calculated from the local numerical wave model SWAN near Saint-Philippe station STPHI (a) and Saint-Pierre station STPI (c). (b-d) Transfer functions between the significant wave height and the seismic amplitude recorded on the vertical component in the PM (at STPHI) and the LPSM (at STPI) frequency bands, respectively. (f) Map of La Réunion Island with the azimuth of the PM (black line) and the LPSM (dotted line) measured by polarization analysis on the RHUM-RUM seismic stations during the main peak of the June 2014 swell event. The swell propagation direction $D p$ is indicated by the arrow.

For northward-propagating austral swell, we evidenced that interaction between the incident swell and the waves reflected on the shore generates local sources of class II SM (referred as LPSM), which are recorded with larger amplitude than the PM signal and that can also be used to describe the extreme austral swell events impacting the southwest coasts of La Réunion.

The ocean waves interaction with the shallow coastal bathymetry generates local sources of PMs that can be used to characterize the swell in terms of period (by spectral analysis), amplitude (by the elaboration of transfer function) and direction (by polarization anal- ysis of the ground displacement). The systematic analysis of the PM noise recorded by the seismic stations deployed temporarily on La Réunion allows us to find a site (STPHI) that displays a high correlation between the variations of the PM amplitude and the significant wave heights computed by the local ocean wave model SWAN, making this site particularly suitable for the seismological austral swell monitoring.

This work demonstrates the ability of using a seismic station as a substitute of an ocean wave gauge by analysing the swell-related microseismic noise (e.g. Iafolla et al. 2015). We show that seismic 
stations, which are easier to install and manage than oceanographic instrumentation, can be sensitive to all type of extreme swell events, whatever the direction they are coming from, and without any risk of damage for the sensor. We can take advantage of the existing global seismic networks to do swell monitoring and to investigate potential sites for renewable energy, particularly in poorly instrumented areas where no ocean wave data are available, by making systematic analysis of the microseismic noise.

\section{ACKNOWLEDGEMENTS}

This project was supported by funding from La Région Réunion and from the RHUM-RUM project. The RHUM-RUM research project (http://dx.doi.org/10.15778/RESIF.YV2011, www.rhum-rum.net) was funded by ANR (Agence Nationale de la Recherche) in France (project ANR-11-BS56-0013), and by DFG (Deutsche Forschungsgemeinschaft) in Germany (grants SI1538/2-1 and SI1538/4-1) with additional funding provided by CNRS-INSU (Centre National de la Recherche Scientifique - Institut National des Sciences de l'Univers) program SYSTER. Seismic instruments used in this study were provided by the Universities of Muenster, Bonn and La Réunion. The RHUM-RUM data set (http://dx.doi.org/10.15778/RESIF.YV2011) has been assigned the FDSN network code YV and is hosted and served by the French RESIF data centre (http://seismology.resif.fr). Data will be freely available by the end of 2017. Thanks to E. Delcher for his help during installation and maintenance of the seismic stations. We thank C. Pequegnat and D. Wolyniec at RESIF for their continuous support integrating, verifying and maintaining data and metadata at the RESIF data centre. RESIF (Réseau Sismologique and Géodésique Français) is a French national research infrastructure, recognised as such by the French Ministry of Education and Research. RESIF is managed by a consortium composed of 18 research institutions and universities in France and is additionally supported by a public grant overseen by the French National Research Agency (ANR) as part of the 'Investissements d'Avenir' program (reference: ANR-11-EQPX-0040) and the French Ministry of Ecology, Sustainable Development and Energy. We are grateful to D. Reymond for the Seismic Toolkit software (STK, available at http://seismic-toolkit.sourceforge.net) and particularly for the SVDS program that has been used for the swell polarization analysis. Thanks to the GEOSCOPE seismological network for operating the station RER, Météo France for providing quantitative cyclone data, the society NortekMed and the DDE (Direction Départementale de l'Équipement) for providing buoy data. This is IPGP (Institut de Physique du Globe de Paris) contribution 3788.

\section{REFERENCES}

Ardhuin, F., Stutzmann, E., Schimmel, M. \& Mangeney, A., 2011. Ocean wave sources of seismic noise, J. geophys. Res., 116, C09004, doi:10.1029/2011jc006952.

Ardhuin, F., Balanche, A., Stutzmann, E. \& Obrebski, M., 2012. From seismic noise to ocean wave parameters: general methods and validation, J. geophys. Res., 117, doi:10.1029/2011JC007449.

Barruol, G. \& Sigloch, K., 2012. RHUM-RUM experiment, 2011-2015, code YV (Réunion Hotspot and Upper Mantle - Réunion's Unterer Mantel) funded by ANR, DFG, CNRS-INSU, IPEV, TAAF, instrumented by DEPAS, INSU-OBS, AWI and the Universities of Muenster, Bonn, La Réunion; RESIF - Réseau Sismologique et géodésique Français, doi:10.15778/RESIF.YV2011.
Barruol, G. \& Sigloch, K., 2013. Investigating La Réunion hot spot from crust to core, EOS, Trans. Am. geophys. Un., 94, 205-207.

Barruol, G., Reymond, D., Fontaine, F.R., Hyvernaud, O., Maurer, V. \& Maamaatuaiahutapu, K., 2006. Characterizing swells in the southern Pacific from seismic and infrasonic noise analyses, Geophys. J. Int., 164, $516-542$.

Barruol, G., Davy, C., Fontaine, F.R., Schlindwein, V. \& Sigloch, K., 2016. Monitoring austral and cyclonic swells in the "Iles Eparses" (Mozambique channel) from microseismic noise, Acta Oecol., 72, $120-128$.

Beucler, É., Mocquet, A., Schimmel, M., Chevrot, S., Quillard, O., Vergne, J. \& Sylvander, M., 2014. Observation of deep water microseisms in the North Atlantic Ocean using tide modulations, Geophys. Res. Lett., 42, doi:10.1002/2014GL062347.

Booij, N., Ris, R.C. \& Holthuijsen, L.H., 1999. A third-generation wave model for coastal regions: 1 . Model description and validation, J. geophys. Res., 104, 7649-7666.

Bromirski, P.D. \& Duennebier, F.K., 2002. The near-coastal microseism spectrum: spatial and temporal wave climate relationships, J. geophys. Res., 107, doi:10.1029/2001JB000265.

Bromirski, P.D., Duennebier, F.K. \& Stephen, R.A., 2005. Midocean microseisms, Geochem. Geophys. Geosyst., 6, Q04009, doi:10.1029/2004GC000768.

Bromirski, P.D., Stephen, R.A. \& Gerstoft, P., 2013. Are deep-oceangenerated surface-wave microseisms observed on land?, J. geophys. Res., 118, 3610-3629.

Cordier, E., Poizot, E. \& Méar, Y., 2012. Swell impact on reef sedimentary processes: A case study of the La Réunion fringing reef, Sedimentology, 59, 2004-2023.

Davy, C., Barruol, G., Fontaine, F.R., Sigloch, K. \& Stutzmann, E., 2014. Tracking major storms from microseismic and hydroacoustic observations on the seafloor, Geophys. Res. Lett., 41, doi:10.1002/2014GL062319.

Davy, C., Stutzmann, E., Barruol, G., Fontaine, F.R. \& Schimmel, M., 2015. Sources of secondary microseisms in the Indian Ocean, Geophys. J. Int., 202, 1180-1189.

Fontaine, F.R., Barruol, G., Kennett, B.L.N., Bokelmann, G.H.R. \& Reymond, D., 2009. Upper mantle anisotropy beneath Australia and Tahiti from $P$-wave polarization - implication for real-time earthquake location, J. geophys. Res., 114, doi:10.1029/2008JB005709.

Gerstoft, P., Shearer, P., Harmon, N. \& Zhang, J., 2008. Gobal P, PP, and PKP wave microseisms observed from distant storms., Geophys. Res. Lett., 35, doi:10.1029/2008GL036111.

Hasselmann, K., 1963. A statistical analysis of the generation of microseisms, Rev. Geophys., 1, 177-210.

Herrmann, R.B., 2013. Computer program in seismology: an evolving tool for instruction and research, Seismol. Res. Lett., 84, $1081-1088$

Iafolla, L., Fiorenza, E., Iafolla, V.A., Carmisciano, C., Montani, L., Burlando, M., De Gaetano, P. \& Solari, G., 2015. OS-IS A new method for the sea waves monitoring, IEEE, doi:10.1109/OCEANSGenova.2015.7271432.

Koper, K.D. \& Burlacu, R., 2015. The fine structure of double-frequency microseisms recorded by seismometers in North America, J. geophys. Res., 120, 1677-1691.

Koper, K.D., Seats, K. \& Benz, H., 2010. On the composition of Earth's short-period seismic noise field, Bull. seism. Soc. Am., 100, 606-617.

Lacoss, R.T., Kelly, E.J. \& Toksöz, M.N., 1969. Estimation of seismic noise structure using arrays, Geophysics, 34, 21-38.

Longuet-Higgins, M.S., 1950. A theory of the origin of the microseisms, Phil. Trans. R. Soc. A, 243, 1-35.

Longuet-Higgins, M.S., 1952. Can sea waves cause microseisms?, in Proceedings of the Symposium on Microseisms, Harriman, NY, Vol. 306, pp. 74-93.

Nishida, K., Kawakatsu, H., Fukao, Y. \& Obara, K., 2008. Background Love and Rayleigh waves simultaneously generated at the Pacific Ocean floors, Geophys. Res. Lett., 35, L16307, doi:10.1029/2008GL034753. 
Obrebski, M.J., Ardhuin, F., Stutzmann, E. \& Schimmel, M., 2012. How moderate sea states can generate loud seismic noise in the deep ocean, Geophys. Res. Lett., 39, L11601, doi:10.1029/ $2012 \mathrm{gl051896.}$

Peterson, J., 1993. Observation and modeling of seismic background noise. Open File Rep., U.S. Geol. Surv., 93-322, 1-95.

Stutzmann, E., Schimmel, M., Patau, G. \& Maggi, A., 2009. Global climate imprint on seismic noise, Geochem. Geophys. Geosyst., 10, doi:10.1029/2009gc002619.
Stutzmann, E., Ardhuin, F., Schimmel, M., Mangeney, A. \& Patau, G., 2012. Modelling long-term seismic noise in various environments, Geophys. J. Int., 191, 707-722.

Tanimoto, T. \& Alvizuri, C., 2006. Inversion of the HZ ratio of microseisms for $S$-wave velocity in the crust, Geophys. J. Int., 165, 323-335.

Tanimoto, T., Hadziioannou, C., Igel, H., Wasserman, J., Schreiber, U. \& Gebauer, A., 2015. Estimate of Rayleigh-to-Love wave ratio in the secondary microseism by colocated ring laser and seismograph, Geophys. Res. Lett., 42, doi:10.1002/2015GL063637. 